\title{
Collaborative Design Thinking (CoDeT): A Co-design Approach for High Child-to-adult Ratios
}

Cite as follows:

Maarten Van Mechelen, Ann Laenen, Bieke Zaman, Bert Willems, Vero Vanden Abeele, Collaborative Design Thinking (CoDeT): A co-design approach for high child-to-adult ratios, International Journal of HumanComputer Studies, Volume 130, 2019, Pages 179-195, ISSN 1071-5819,

https://doi.org/10.1016/j.ijhcs.2019.06.013.

\section{Maarten Van Mechelen}

Faculty of Industrial Design Engineering (TU Delft)

Landbergstraat 15, 2628 CE Delft, Netherlands

Center for Computational Thinking \& Design (Aarhus University)

Helsingforsgade 14, 8200 Aarhus N, Denmark

Mvanmechelen@cc.au.dk

Ann Laenen

Department of Digital Arts, University of Malta

Msida MSD 2080, Malta

Ann.laenen@um.edu.mt

Bieke Zaman

Meaningful Interactions Lab (Mintlab, KU Leuven - imec)

Parkstraat 45 box 3605 in 3000 Leuven, Belgium

Bieke.zaman@kuleuven.be

Bert Willems

PXL-MAD, PXL University College

Elfde-Liniestraat 24, B-3500 Hasselt, Belgium

Faculty of Architecture \& Arts, Hasselt University

Agoralaan, building D, B-2590 Diepenbeek, Belgium

Bert.willems@pxl.be

Vero Vanden Abeele

e-Media Lab (KU Leuven)

Vesaliusstraat 13 in 3000 Leuven, Belgium

Vero.vandenabeele@kuleuven.be 


\section{ABSTRACT}

This paper presents the Collaborative Design Thinking (CoDeT) co-design approach, its theoretical framework, and its application in a case study with 49 children aged 9 to 10 in two schools. CoDeT aims to scaffold children's collaboration and design thinking in co-design settings characterised by a high child-to-adult ratio (ca. 1 adult for 15 to 20 children), such as schools, museums and maker spaces. In these settings, children have to work relatively independent from adults who become guides on the side. This can be challenging due to children's limited understanding of the design process and their lack of skills to collaborate productively towards a shared design goal. CoDeT addresses these challenges by integrating principles of Social Interdependence Theory (SIT) and Design Thinking (DT), which together form the theoretical backbone of the approach. CoDeT was first applied in a case study and yielded promising results in terms of children's collaboration and design thinking skills, yet possible improvements were found. The insights of this case study informed the revised version of CoDeT presented at the end of this article, in a what-why-how structure, allowing researchers and practitioners to apply the co-design approach in a wide variety of contexts characterised by high child-to-adult ratios.

\section{Keywords}

Co-design; Participatory Design; Child-computer Interaction; Design Methods; Children; Design Thinking; Collaboration; Social Interdependence Theory

\section{INTRODUCTION}

Designing technology for and with children is a valuable but challenging endeavour. Valuable, because it can empower children, result in unexpected design ideas and offer insight in children's unique view of the world. Challenging, because children are fundamentally different from adults, and often lack design thinking and collaboration skills, necessary to engage in co-design activities. Moreover, design researchers are usually not trained as educators and may lack the skills to facilitate co-design activities, especially in situations with high child-to-adult ratios such as schools, museums and maker spaces. This paper addresses these challenges by offering a theory-driven yet hands-on approach to designing technology for and with children, referred to as Collaborative Design Thinking (CoDeT).

In this paper, co-design is understood as a technique or tool to enable people who are not trained as designers, such as children, to participate in the design process by the act of making and giving meaning to things. Co-design is often used interchangeably with Participatory Design (PD), but the latter is regarded as an overarching methodology or design philosophy rather than a specific technique or tool (Spinuzzi, 2005). PD asserts that envisioned users of technology and other stakeholders should play a critical role in its design (Schuler and Namioka, 1993). Consequently, to render an approach as PD, the use of co-design techniques needs to go hand in hand with a process of reciprocal learning and the sharing of decision-making power between all stakeholders (Van Mechelen, 2016; 2019).

Different co-design settings are possible, each with their own methodological implications. Children may team up with design researchers directly, or they may collaborate with peers while design researchers take on a facilitating role. The former is a useful strategy for low child-to-adult ratios (ca. 1 adult for 2 to 5 children) such as in a design lab (e.g., Alborzi et al., 2000; Druin, 1999; Guha et al., 2013), the latter for high child-to-adult ratios (ca. 1 adult for 15 to 20 children) such as in schools, museums and maker spaces (e.g., Barendregt et al., 2018; Dodero et al., 2014; Horton et al., 2012). An important advantage of co-design sessions at high child-toadult ratios is that a broad variety of children and, hence, perspectives, can be included in the design process, guided by only one or two design researchers. On the downside, children need to work relatively independently from adults, requiring more self-regulation in their creative collaborations with peers. In order to achieve 
this, the CoDeT approach relies on insights from (1) the field of Design Theory, by integrating a Design Thinking model proposed by Thoring Müller (2011) and (2) the field of Cooperative Learning, by integrating principles of Social Interdependence Theory (Johnson and Johnson, 2009, 2005). Based on these theoretical foundations, CoDeT aims to create optimal conditions for children to collaborate towards a shared design goal, in co-design settings characterised by a high child-to-adult ratio.

The paper first discusses the history of designing technology for and with children. Afterwards, the theoretical foundations of CoDeT in Design Thinking, Cooperative Learning and Social Interdependence Theory are introduced, followed by a description of a case study involving 49 children between 9 and 10 years old in two schools. The results from this case study informed the revised version of the CoDeT approach, which is presented in a what-why-how structure. The paper concludes with a discussion of CoDeT's main strengths and limitations, and areas for further research.

\section{BACKGROUND}

\section{Children as Co-designers}

A core value for the Child-Computer Interaction $(\mathrm{CCl})$ community is to give children a voice in the research and design process by representing and respecting their interests (Read and Markopoulos, 2013). This recurring emphasis on having children participate in designing the technologies that will have an impact on their lives and environments has its roots in constructivism. Characteristic of constructivism is the idea that children actively construct their own knowledge through experiences (i.e., through relating to people and things), and that this construction is based on each child's idiosyncratic knowledge structures (Ackerman, 2001; Resnick, 2017). This contrasts with the view that children can simply store knowledge imparted by others and that they all perceive and learn from an experience in the same way (Hourcade, 2008). Constructivism implies that there is not one but a multiplicity of childhoods that need to be understood, each with their own power, status, social and economic differentials (Dawes, 2000). This consideration has led to a critical examination of traditional methods (e.g. questionnaires, checklists, interviews) that positioned children as rather passive in research (Veale, 2005). In child research throughout the 1990s, creative methodologies were developed that drew on inventive and imaginative processes, such as storytelling, drama and drawing (e.g., Andersson, 1994; Donald et al., 1997; Golomb, 1992; Woodhead, 1999). These techniques served as constructivist tools to assist children in describing and analysing their experiences and give meaning to them. Since then, participatory research with children has focused on the generation of knowledge, as opposed to knowledge 'gathering' (Veale, 2005). Instead of merely extracting knowledge from children, the ways in which children engage in world making in their everyday lives became the focal point (Flick, 2009).

The same evolution could be witnessed in the $\mathrm{CCl}$ community. Initially, researchers sought for age appropriate evaluation methods to test working prototypes or existing technologies (e.g., Gibson et al., 2001; Read, 2008; van Kesteren et al., 2003). In line with a wider trend in $\mathrm{HCl}$, these evaluation methods first stemmed from cognitive theory and aimed to increase usability, productivity and control (Read et al., 2011). Involving children as testers only, however, assumes an asymmetrical relationship between children and designers, because designers have the sole responsibility and decision-making power to translate findings into suitable solutions. Under the influence of PD, children's role as passive users was gradually transformed to that of active participants (Read and Markopoulos, 2013).

Scaife and colleagues were among the first to give children a more active role in the design process of technology for children (Scaife et al., 1997). They used a blend of low-tech prototyping techniques borrowed from PD to involve children as native informants at certain stages of the design process, termed Informant Design. Their aim was not only to evaluate a prototype and make changes based on the knowledge gained from the 
tests (children as testers), but also to use children's input in the early design stages to discover new opportunities and reframe the design challenge (Scaife and Rogers, 1999). Other researchers who helped to broaden the role of children in the design process are Druin and colleagues (e.g., Druin, 2002, 1999; Druin et al., 2007; Guha et al., 2013). They consistently advocated equal partnership with children, which is a core tenet of Druin's Cooperative Inquiry method (Druin, 1999). Instead of working with many different children over short periods of time, Druin aims for an ongoing partnership with a small group of children throughout the entire design process. The goal of Cooperative Inquiry is to support intergenerational teams in developing new technologies for children by giving them a voice in the process (Druin, 1999).

The uptake of Informant Design and Cooperative Inquiry in the $\mathrm{CCl}$ community has led to a proliferation of codesign techniques in different application domains and use contexts. Some of these techniques fit within the Cooperative Inquiry approach, such as Mixing Ideas (Guha et al., 2004), Layered Elaboration (Walsh et al., 2010), and Distributed Co-design (Walsh et al., 2012). Other examples include the work of Gielen $(2008,2007)$ who used explorative design techniques, referred to as Contextmapping, to learn about the needs, wishes and experiences of children. These insights are useful in the early stages of the design process to more accurately define the design problem and product category (Gielen, 2008). Horton and colleagues (2012) in turn, developed an approach called Mad Evaluation Session with School children (MESS). With this approach, design researchers can carry out design and evaluation sessions with the whole class in a school friendly manner (Horton et al., 2012). A theoretical lens is offered by Iversen and colleagues (2013), who looked at children's motivation in co-design activities relying on Cultural-Historical Activity Theory (CHAT). The authors demonstrate how different tools (e.g. rewards, storytelling, collaboration) can be employed to engage children in codesign practices, and how this resonates with a theoretical understanding of motivation (Iversen et al., 2013).

More recently, $\mathrm{CCl}$ researchers have critically examined the different roles of children in the design process. Van Doorn and colleagues (2013) extended the role of children from design partners to co-researchers. In a systematic approach, they prepare children to collaborate in setting up and conducting contextual user research and analysing the data. livari and colleagues (2015) proposed a framework to study how genuine children's participation really is. They argue that, despite researchers' best intentions, children are often not allowed real responsibility because adults make the final decisions. Similarly, Barendregt and colleagues (2016) developed a tool, the Role Definition Matrix, to describe more precisely the involvement of children in technology design. Schepers and colleagues (2018), in turn, point towards the role of the child as process designer. In this role, children do not merely participate in the design process, but also co-design the process itself. In a similar strand of thought, Iversen and colleagues (2017) advocated the role of protagonist. The objective for children is not only to design technology, but "to develop new insights, design abilities, and a critical stance towards technology through their engagement in design work" (Iversen et al., 2017).

Historically, in $\mathrm{CCl}$ literature, there has been more focus on the roles of children than adults within the technology design process, but lately $\mathrm{CCl}$ researchers have started to address this gap. Benton and colleagues (2015) did an extensive literature review of the roles of adults working with children with special educational needs and/or disabilities (SEND). They discerned five different roles for adults, acting either as facilitators, motivators, caregivers, proxies participating on children's behalf, and/or co-designers. Yip and colleagues (2017) in turn, looked at what constitutes an equal partnership between adults and children, proposing four dimensions (facilitation, relationship building, design-by-doing, elaboration) to evaluate adult-child interactions and aid the understanding of equitable co-design practices.

Despite this valuable body of work, co-design with children remains a fertile area for further research. Of particular interest are strategies to improve children's collaboration and design thinking skills in co-design settings with a high child-to-adult ratio (ca. 1 adult for 15 to 20 children) such as schools, museums and maker spaces. Previous work by the authors revealed that, in such settings, children might lack problem ownership and a 
basic understanding of the design process. Moreover, while working together, they may get caught up in challenging intragroup or co-design dynamics (e.g. Free Riding, Groupthink, Apart Together) that hamper their creativity and problem solving abilities (Van Mechelen et al., 2015b, 2014a). In co-design settings with high child-to-adult ratios, these challenges are amplified because children have to work relatively independently from adults who take on a facilitating role, becoming 'guides on the side'. The CoDeT approach addresses these challenges by relying on insights in the fields of Design Theory and Cooperative Learning, which are outlined in the next sections.

\section{Scaffolding Design Thinking in Co-design Latent and Collaborative Creativity}

In this paper, co-design is defined as a set of constructivist techniques and tools to enable people to participate in the design process by the act of making and giving meaning to things. This definition of co-design builds on two principles that differ from common thinking.

The first principle upholds that everyone is creative, although many people are not in the habit of using or expressing their creativity; their creativity is likely to be latent. Sanders and William (2001) argue that there is a wellspring of creativity that all people have when it comes to experiences that are meaningful to them, and that people are in a position to participate and generate ideas in the design process based on their knowledge and expertise (Sanders and William, 2001). The same idea is reiterated by Alborzi and colleagues (2000) and Druin (2002), arguing that everybody has unique experiences and skills, no matter what age or discipline. This notion that everyone can contribute to the design process can be traced back to Papanek's seminal book 'Design for the Real World' in which he states that: "All men are designers. All what we do, almost all the time, is design, for design is basic to all human activity. Any attempt to separate design, to make it a thing-by-itself, works counter to the fact that design is the primary underlying matrix of life" (Papanek, 1985: 3).

The second principle posits that co-design is a form of collaborative creativity in which multiple actors promote discussion and expand the range of options. This view on creativity contradicts the idea of the lone genius who wrestles with a problem and breaks through various blocks to find a clever solution. Rather, creativity is seen as embedded in a community of practice with changing standards and requiring a social process for approval (Shneiderman, 2000; Spendlove, 2005).

Both principles, that everyone can contribute creatively to the design process based on their unique experiences, and that co-design is a type of collaborative creativity, form the starting point for the CoDeT approach. CoDeT relies on design thinking to enable children to express their latent creativity - i.e., creating something novel, valuable, useful and generative (Plucker et al., 2004; Stokes, 1999) - in close collaboration with their peers.

\section{Design Thinking}

Design thinking (DT) aims to transfer designerly methods, tools and processes to other areas or people, in this case children, who are not trained as designers (Brown, 2008). A central feature of DT is the recursive relationship between projective or divergent thinking (i.e., creating choices) with reflective or convergent thinking on the impact of the projection (i.e., making choices) (Kimbell, 2000). Separating the generation of ideas, in which the possibility space expands, and the evaluation of ideas, in which the possibility space reduces, is regarded good practice for creativity (Brown, 2008; Kryssanov et al., 2001; Sutton and Hargadon, 1996).

Although varying DT models exist, a particular model of interest is that of Thoring and Müller (2011). The consecutive steps of their model suggest a linear sequence, but several iterations may be required to run through the model (see Figure 1). 


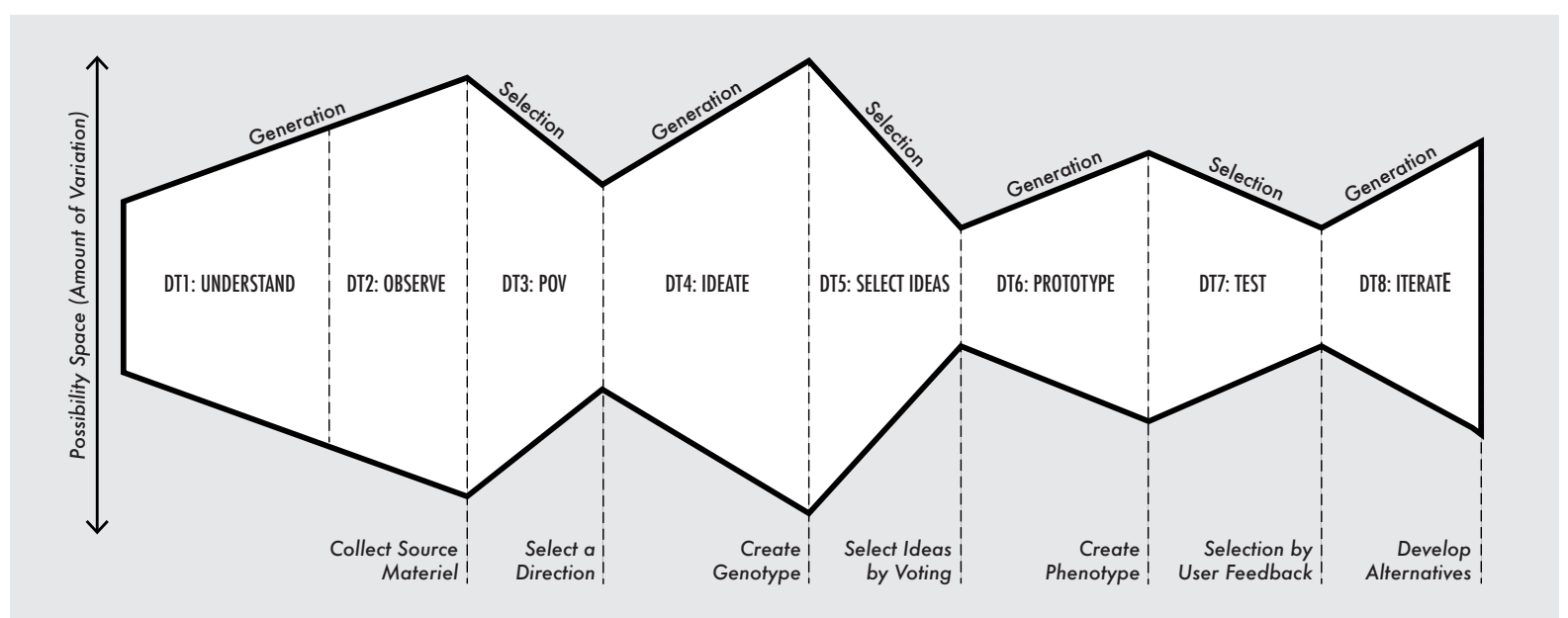

Figure 1: Design Thinking (DT) model proposed by Thoring and Muller (2011) that consists of a sequence of divergence-convergence steps that alternately expand and reduce the possibility space.

In the first step (DT1), Understanding, existing information about the topic is gathered through secondary research (Thoring and Müller, 2011). The second step (DT2), Observing, is based on a qualitative research approach including techniques such as depth interviews, observations, and generative techniques. Different insights are collected about actual problems, people's needs and wishes, and technological possibilities, which are then shared with the design team (Thoring and Müller, 2011). Step 1 and 2 are often referred to as the fuzzy front end of design because of the ambiguity and chaotic nature that characterizes it (Sanders and Stappers, 2008). At the fuzzy front end, the possibility space expands, meaning that as many options as possible are considered.

In the third step (DT3), Point of View, the insights of the first two steps are synthesized into a problem statement that determines the future focus. In doing so, the possibility space reduces for the first time. The point of view functions as a micro-theory about the design problem. It reflects the users' perspectives and is often visualized (e.g., through personas, a mind map or a diagram) to enhance communication with the design team (Thoring and Müller, 2011). The key is to establish a point of view that provides enough focus to move the design team forward but, at the same time, is open-ended enough for problem-finding creativity to emerge (Sawyer, 2008).

In the fourth step (DT4), Ideation, ideas are generated to solve the problem and the possibility space typically expands to its maximum. These ideas are often based on a recombination and mutation of previous insights and experiences (Thoring and Müller, 2011). To foster this process, different ideation techniques can be used that fall under the umbrella term of brainstorming (e.g., gamestorming, brainwriting, extreme ideation). Osborn (1953) was the first to coin the term brainstorming in his book Applied Imagination. He proposed four basic rules for brainstorming ideas: "do not criticize", "quantity is wanted", "combine and improve suggested ideas", and "say all ideas that come to mind no matter how wild" (Osborn, 1953. Other rules that are sometimes added are "be visual" and "stay focused on topic" (Sutton and Hargadon, 1996).

In the fifth step (DT5), Selection, similar ideas are grouped together and the most promising ideas are selected, which reduces the possibility space and sets the focus on a small set of ideas (Thoring and Müller, 2011). These ideas are then visualized and further developed in the sixth step (DT6), Prototyping. Usually, more than one prototype is developed which can be either a paper artefact, a working model or any other tangible artefact. During prototyping, the possibility space is slightly opened up again because new details and alternatives are considered to improve the solution (Thoring and Müller, 2011).

In the seventh step (DT7), Testing, the prototype is taken to the users to gather feedback. A selection of the feedback can be used to revise the prototype in the eighth and final step (DT8), Iteration. Depending on the feedback, it may be necessary to go back to the first two steps of the DT model, Understand and Observe, to gather additional insights or rethink the proposed solution entirely. Collecting feedback is an iterative process 
of evaluation and adaptation. These iterations widen the possibility space again because alternative solutions and improvements are to be considered (Thoring and Müller, 2011).

The dialectic of divergence and convergence in Thoring and Müller's (2011) DT model has found much acclaim in the design community. The different steps of the model are implemented in the CoDeT approach to support children in reflecting on their experiences and tapping into their creative potential (see Figure 3).

In addition to introducing children to the creative mechanisms of design thinking, CoDeT aims to scaffold children's collaboration in co-design settings characterised by a high child-to-adult ratio.

\section{Scaffolding Collaboration in Co-design}

\section{Interactivity, Synchronicity and Negotiability}

Co-design, as a form of collaborative creativity, requires that multiple actors work together towards a shared design goal. Productive collaboration can be hard to achieve though, especially when children lack motivation and/or skills to work in a team setting, which is further complicated in co-design settings with high child-toadult ratios where only few adults facilitate the process (Van Mechelen et al., 2015b, 2014a).

This raises the question of what constitutes productive collaboration. Educational scientist Dillenbourg (1999) distinguishes three criteria for collaborative situations among children which provide an interesting lens to look at children's team work in co-design activities: interactivity, synchronicity and negotiability. The first criterion asserts that collaborative situations should be interactive, and that the degree of interactivity is determined by the extent to which interactions between children influence their cognitive processes. This implies that the quality and impact of the interactions is more important than their frequency. The second criterion upholds that collaboration requires synchronous communication, meaning that a speaker expects the listener to wait for the message and process it as soon as it gets delivered. Synchronicity, however, is a social rule rather than a strict parameter. Depending on the context and medium, social rules may differ and children may create new ways of maintaining the subjective feeling of synchronicity. Negotiability, the third criterion, prescribes that in collaborative situations children do not impose their view on the sole basis of their authority. At least to some extent, children need to be able to argue for their point of view and negotiate it in an attempt to convince other children (Dillenbourg, 1999).

To scaffold interactivity, synchronicity and negotiability in co-design settings with a high child-to-adult-ratio, CoDeT relies on an educational approach referred to as Cooperative Learning, and its underlying theoretical framework Social Interdependence Theory.

\section{Cooperative Learning and Social Interdependence Theory}

The term Cooperative Learning $(\mathrm{CL})$ is used to refer to a broad range of teaching strategies in which two or more children form teams to learn or attempt to learn something together (Krol-Pot, 2005). In a CL environment, children are not only focused on their own learning, but also on the learning of their group members. In theory, children in a $\mathrm{CL}$ environment have equal status and equal opportunities for success, implying a symmetrical relationship (Krol-Pot, 2005). CL has its roots in socio-constructivism and sees learning governed as much by social and situational factors as by cognitive ones. This means that thinking and learning processes do not only take place in the heads of children, but in constant interaction with the social, cultural and physical environment (Resnick, 1991; Shuell, 1996; Van der Linden et al., 1999). This conception aligns well with the notion of co-design as a form of collaborative creativity.

An interesting approach to CL can be found in the work of Johnson and Johnson (1994). In their approach, group goals and incentives are combined with team building activities and group self-evaluations, to strength- 
en children's motivation to learn together. For Johnson and Johnson, who based their work on Lewin (1948) and Deutsch $(1962,1949)$, Social Interdependence Theory (SIT) is an important perspective that guides their research into CL. From this theoretical perspective, it is assumed that the way in which interdependence is structured determines how individuals interact, which, in turn, determines outcomes (see Figure 2) (Johnson and Johnson, 2005, 1989). In their approach to $\mathrm{CL}$, five mediating principles are structured in classroom lessons to facilitate children's collaboration: positive interdependence, individual accountability, face-to-face promotive interaction, interpersonal and small-group skills, and group processing. The combination of these five principles, argued by Johnson and Johnson (2005), is essential for a situation to be collaborative (see Figure 2). The principles are embedded in the CoDeT approach to create optimal conditions for children to collaborate with their peers.

The first principle (SIT1), positive interdependence, means that people have to work together to accomplish a goal, and that their efforts are important for the entire group. Negative interdependence, on the other hand, implies that there is a negative correlation among people's goal attainments such as in a competitive situation. Three types of positive interdependence can be distinguished in a CL environment: outcome, means and boundary interdependence. Outcome interdependence (SIT1a) means that people perceive collaboration as essential to reach a shared goal, means interdependence (SIT1b) implies that people are dependent on each other for resources and abilities, and boundary interdependence (SIT1C) means that people are intrinsically motivated to help each other because they experience a shared identity. Ideally, these three complimentary forms of positive interdependence are combined in a CL environment.

The second principle (SIT2), promotive interaction, refers to behaviours whereby people support each other in achieving a shared goal. Such caring and committed relationships are strengthened when people are positively interdependent (i.e., SIT1)). In a CL situation, children are engaged in promotive interactions when they encourage each other and work together to achieve one or more mutual learning goals. On the contrary, negative interdependence, such as in a competitive situation, is characterized by oppositional or negative interactions that hinder other children's goal achievement.

The third principle (SIT3), individual accountability, refers to people being held responsible for their contribution in achieving a shared goal. In CL, it is important that children realize that they themselves are responsible for the teamwork and that they have to make an effort to make the group as a whole succeed. Individual accountability makes it possible for the teacher and the team members to detect individual contributions, which, in turn, can result in feelings of responsibility among children for completing their share of the work and facilitating the work of others in the group.

The fourth principle (SIT4), interpersonal and small-group skills, is a requirement for high-quality collaboration and, for children, to be productive in a CL setting. These skills often need to be taught to children and include active listening, turn taking, good questioning and argumentation. The quality and quantity of learning in $\mathrm{CL}$ depends on children's interpersonal and small-group skills as well as their motivation to use these skills. These skills are essential to cope with the stresses and strains of working in a team, and are a precondition for promotive interactions to occur (i.e., SIT2).

The fifth principle (SIT5), group processing, implies that team members reflect on the team's progress in achieving a shared goal. When group processing is implemented in a CL situation, children discuss which actions and behaviours were helpful and less helpful, and they decide which actions to continue or change. The underlying rationale is that, to continuously improve their work over time, children have to reflect on their working relationships and how well they are applying the interpersonal and small-group skills (i.e., SIT4) required for effective collaboration. Group processing has a positive impact on the development of these skills and, hence, fosters promotive interactions (i.e., SIT2). 


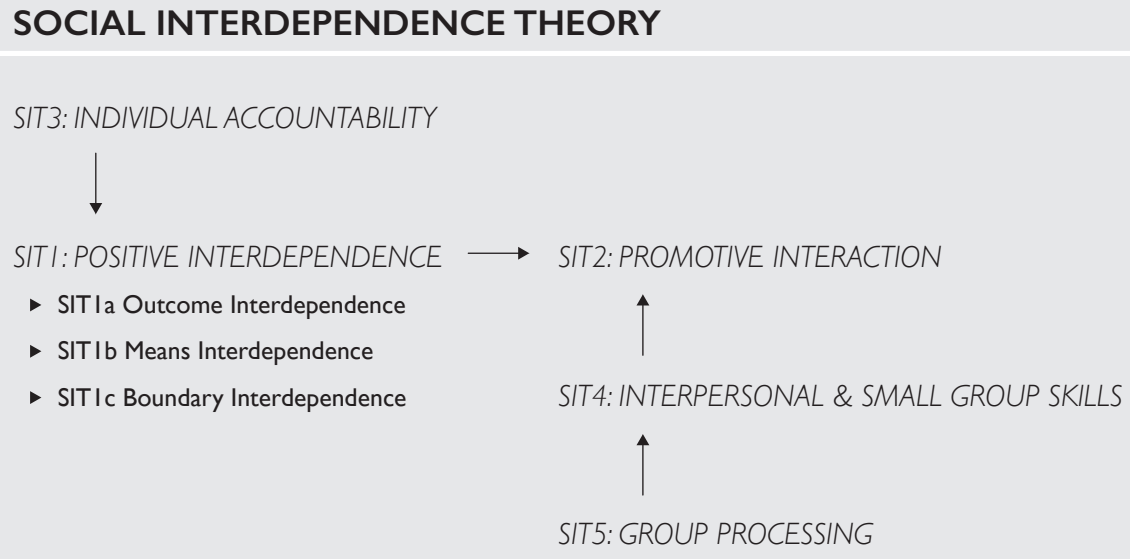

Figure 2: The five mediating principles for effective collaboration according to Social Interdependence Theory's (SIT); the arrows indicate how the principles reinforce one another, increasing the amount of promotive interactions between individuals (Johnson and Johnson, 1994; 1999).

According to Johnson and Johnson (1999), the role of the teacher in CL should be that of a guide on the side. The teacher first has to make a number of pre-instructional decisions regarding learning objectives, group composition, role assignments and arrangement of the room and the materials. Then, the teacher has to explain the instructional tasks and the collaborative nature of the lesson. This includes explaining the criteria for success and structuring positive interdependence among team members. Once children start collaborating, the teacher has to monitor the different learning groups, encourage promotive interactions, intervene when needed, and eventually bring the lesson to closure. Finally, the teacher evaluates the results, which includes assessing children's individual achievements, ensuring they understand the effectiveness of their learning, and having them celebrate their teamwork (Johnson and Johnson, 1999).

The five mediating principles to create a $\mathrm{CL}$ environment and the suggested role for the teacher (or in this case the adult facilitator) are implemented in the CoDeT approach to increase the degree of interactivity, synchronicity and negotiability (see Dillenbourg's [1999] criteria for collaborative situations in the previous section) between children during co-design activities (see Figure 3 ).

\section{A Framework for Co-design at High Child-to-Adult Ratios}

SIT's five mediating principles (see Figure 1) and the DT model (see Figure 2) form the backbone of the CoDeT approach. These two theoretical models were merged and modified for co-design settings with high child-toadult ratios, which resulted in the framework presented in Figure 3.

The dialectic of divergence and convergence found in the DT model is used to scaffold children's creativity in CoDeT and to compensate for their lack of experience as co-designers. The first two steps of the DT model, understanding (DT1; divergence) and observing (DT2; divergence), are merged and captured in a sensitizing phase (CoDeT step 2). Sensitizing is a technique used in Contextmapping (Sleeswijk Visser et al, 2005) to open up the possibility space by triggering children's reflection and curiosity about the design theme in a playful and creative way. Participants receive a package with different assignments, which they complete in their own time and environment before the team activities. In CoDeT, these assignments are research-oriented (e.g., keeping track of experiences in a user diary, interviewing peers about the design theme) and aim to deepen children's understanding of the design theme. The next three steps of the DT model, Point of View (DT3; convergence), Ideation (DT4; divergence) and Selection (DT5; convergence) are retained in the CoDeT approach (CoDeT steps 3, 6 and 7). Prototyping (DT6), the next divergent phase, is referred to as Elaboration through 
Making (CoDeT step 8), to emphasize that a selected idea can still evolve while being built. Testing (DT7; convergence) was configured as a peer jury (CoDeT step 9) whereby teams present and evaluate each other's design solution. Depending on the available time, the project is wrapped up after the peer jury or teams can do additional iterations (DT8; divergence) addressing the feedback from their peers (CoDeT step 10). Altogether, the CoDeT approach consists of three divergence-convergence phases constituting one DT cycle that can be iterated multiple times (see Figure 3).

SIT's mediating principles are implemented in CoDeT to mitigate challenging intragroup or co-design dynamics (Van Mechelen et al., 2015, 2014a) and to create optimal conditions for children to collaborate. The three types of positive interdependence (SIT1) are implemented early on in the process (CoDeT step 3): Outcome interdependence (SIT1a) is implemented by explaining the design goal and criteria for success, means interdependence (SIT1b) by allocating roles and responsibilities based on team members' individual strengths, and boundary interdependence (SIT1C) by engaging children in team building activities to create a shared identity. In contrast to a $\mathrm{CL}$ environment, individual accountability (SIT3) is not applied as a formal assessment of each team member's contribution, but by proactively emphasizing each child's unique role in their team and by installing a peer jury (Step 9) in which the team as a whole is evaluated at the end of the co-design process.

Promotive interaction (SIT2), in turn, is not implemented as a separate step but as a guideline for the facilitator who orchestrates the co-design process. At the start of the team activities, the facilitator specifies the kind of interactions that are expected, and which interpersonal and small-group skills (SIT4) this requires (e.g. active listening, providing arguments). During the design activities, the facilitator actively encourages promotive interactions, providing opportunities to practice and reflect on these skills. Related to this, the last principle, group processing (SIT5), is included as a separate step halfway the design activities (CoDeT Step 5). In this step, teams reflect on the collaboration process and the extent to which they applied the skills. They furthermore think of individual actions to improve collaboration, which emphasizes each child's unique role and responsibility in the team.

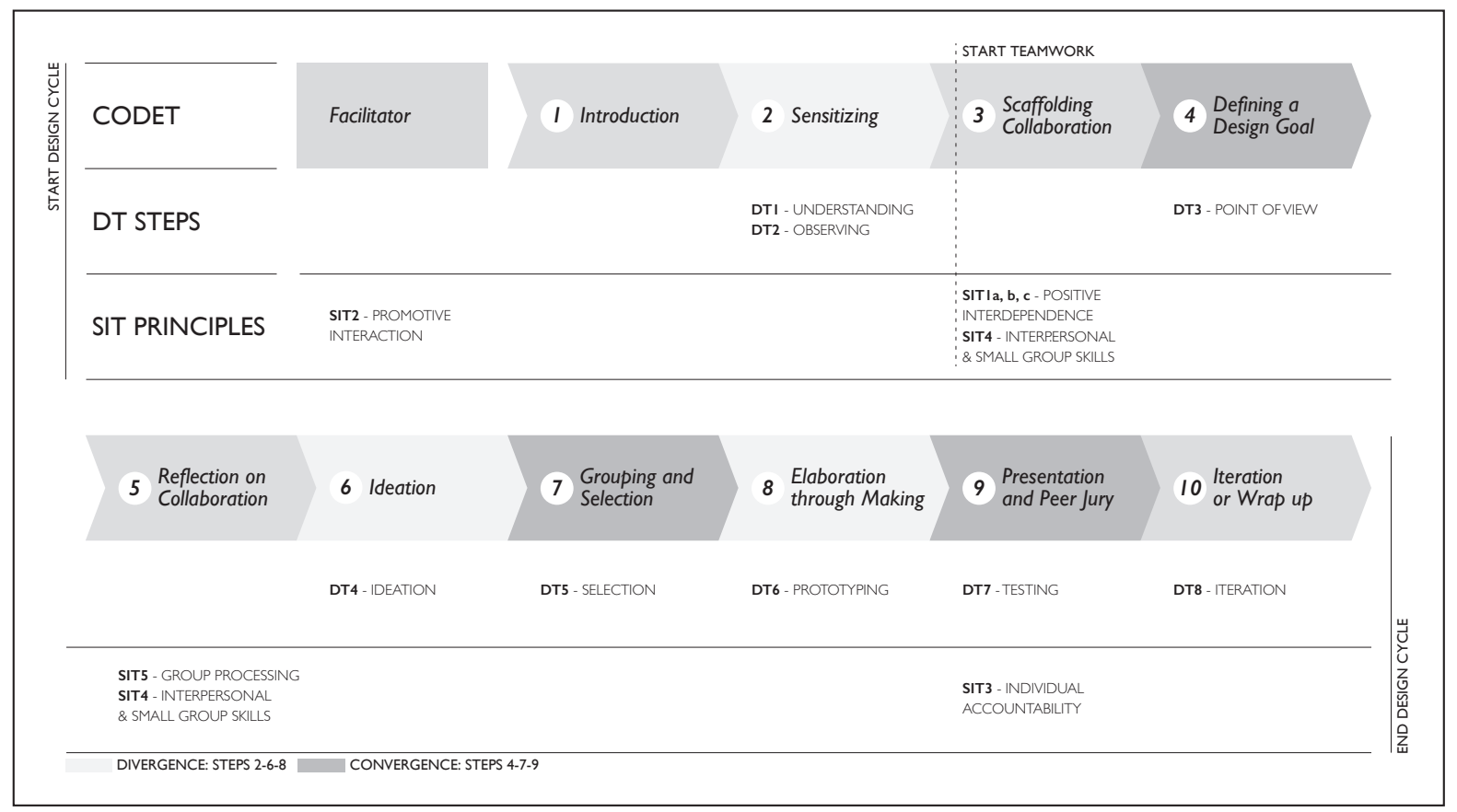

Figure 3: The Collaborative Design Thinking (CoDeT) framework integrates divergent-convergent Design Thinking steps (DT) and the five mediating principles for effective collaboration suggested by Social Interdependence Theory (SIT). 


\section{CASE STUDY}

A case study was conducted to evaluate the CoDeT approach and its underlying theoretical framework (see Figure 3), which integrates DT and SIT. The insights of the case study were used to improve CoDeT; the revised version is presented in section 4 .

\section{Method}

The case study was part of a nationally funded project, called EMSOC, focused on child empowerment. The overall goal was to increase children's emotional and behavioural self-regulation in preventing bullying in the social context of the class group. By empowering the class group, the aim was to increase social cohesion and revert exclusion due to bullying. For that purpose, digital tangible tools were to be developed.

\section{Participants}

Two schools in Flanders, Belgium, participated in the study, with a total of 49 children between 9- and 10years old. These schools were selected purposively, meaning that information rich cases were chosen for indepth study. One school was a catholic school located in an urban region, and the other school was a state school located in a suburban region. This purposive selection of schools offered a varied mix of children in terms of social background, ethnicity and personal strengths.

\section{Researchers}

Two design researchers conducted the co-design activities in the participating schools: one fly-on-the-wall observer who made notes and one facilitator (the $1^{\text {st }}$ author). The lead facilitator discussed the project beforehand with the participating schools to align expectations and to ensure that the co-design activities would fit the school and class culture. One of the tasks handed over to the teacher was dividing the class group in heterogeneous teams of 4 to 6 children with complementary strengths (e.g. based on criteria such as verbal skills, creative abilities, and a collaborative mind-set). After preparing the activities and the materials, the facilitator orchestrated the CoDeT approach.

\section{Data analysis}

The co-design activities were recorded on video and the presentations and discussions at the end of each session were fully transcribed. Immediately after each session, a report was written based on the observation notes and the facilitator's experiences. Video recordings were consulted to gain a better understanding of children's behaviour and to complement the reports. The resulting qualitative data consisted of transcripts of presentations and discussions between children, observation reports complimented with insights from video footage, and design artefacts (i.e., problem statements, selected design ideas and paper prototypes). The thematic analysis of the co-design outcomes (i.e., design ideas, prototypes and knowledge) has been published elsewhere (Derboven et al., 2015; Van Mechelen et al., 2017, 2015a), and will not be discussed here. This paper focuses on evaluating the CoDeT approach and its underlying framework (see Figure 3). For this aim, all five authors annotated the qualitative data (transcripts, reports, pictures of artefacts) and, afterwards, shared their insights and suggestions for improving CoDeT. This was done in several rounds of discussion and reflection, thereby concentrating on the following topics:

- Children's collaboration (i.e., the degree of interactivity, synchronicity and negotiability): how children interacted, made decisions together, dealt with differing voices, motivated each other, etc.

- Children's design thinking abilities: how children separated divergence and convergence of ideas, whether they understood how the different design steps contributed to the final prototype, etc.

- The role of the adult facilitator: the amount and type of help needed, both for class-management (e.g. to manage disputes) and content support (e.g. when a team is stuck), etc. 
Once a consensus was reached between all five researchers, CoDeT was modified accordingly. This revised version is presented in section 4.

\section{Co-design Process}

Applying the CoDeT approach resulted in three visits per school: (1) Introducing the project and individual sensitizing assignments (Step 1 Introduction, Step 2 Sensitizing; ca. 1hour), (2) a first co-design session aimed at improving team cohesion, and exploring and defining a design problem (Step 3 Scaffolding Collaboration, Step 4 Defining a Design Goal, Step 5 Reflection on Collaboration; ca. 3 hours), and (3) a second co-design session aimed at developing a solution, and building and presenting a paper prototype (Step 6 Ideation, Step 7 Grouping and Selection, Step 8 Elaboration through Making, Step 9 Presentation and Peer Jury, Step 10 Iteration or Wrap up; ca. 3 hours). The following subsections briefly describe the activities during each visit.

\section{Visit 1: Introduction and Sensitizing}

When first meeting the children (Step 1: Introduction), the facilitator introduced himself and the design theme (i.e., preventing bullying in the social context of the class). Afterwards, he had a conversation about the design process, explaining that it can be broken down in different steps and that children would collaborate in small teams, and that this would require certain skills such as active listening and good communication. Then, he handed out sensitizing packages with four individual assignments to prepare children for the first co-design session approximately two weeks later (Step 2: Sensitizing). One such assignment was to draw a class with a bad atmosphere, and to explain what makes the atmosphere bad (see Figure 4 - left). As the first divergent phase, sensitizing was expected to trigger children's reflection and curiosity about the design theme, opening up the possibility space. The analysis of these and other sensitizing results provided preliminary insights about children's views about the design theme, and was used as input for the first co-design session.
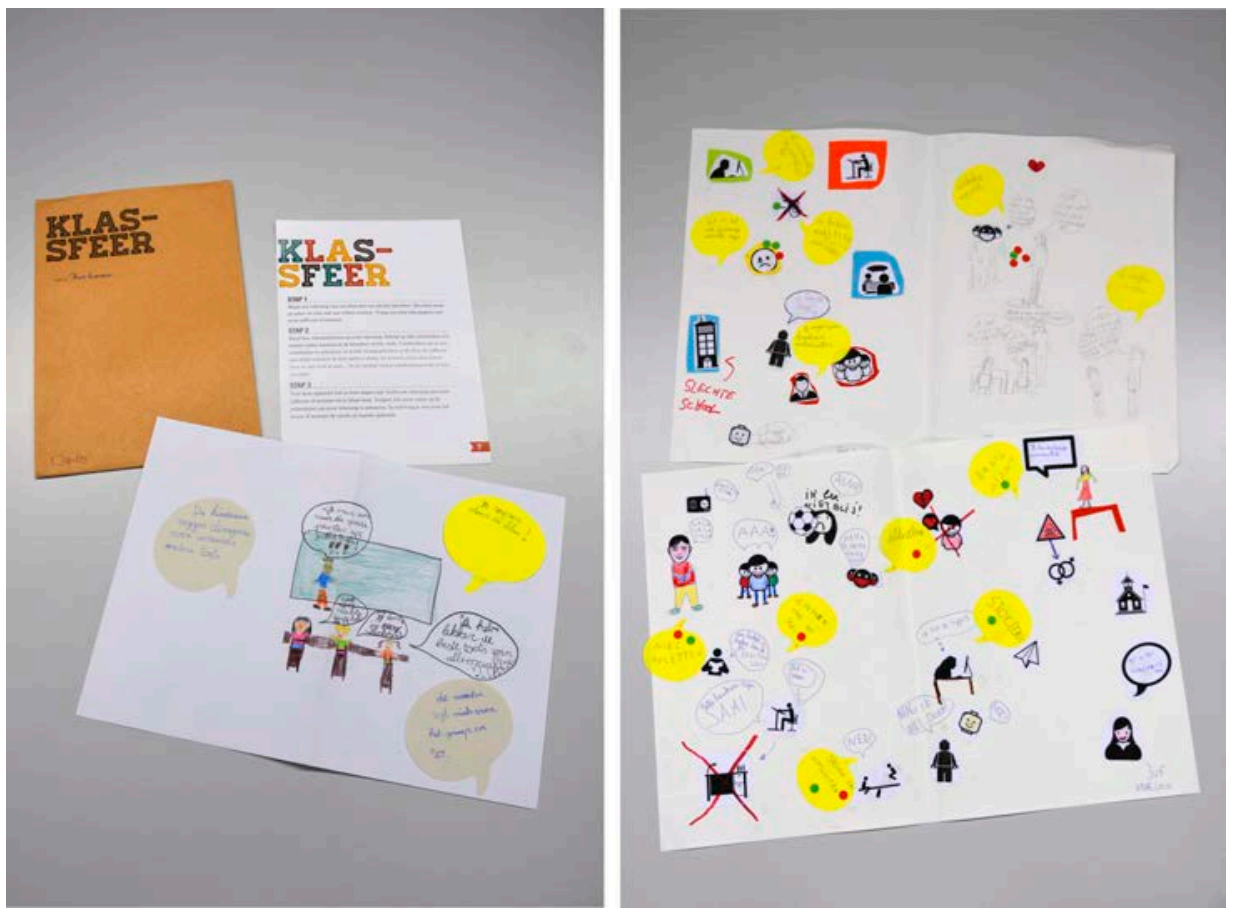

Figure 4: A sensitizing assignment and the resulting drawing of a class with a bad atmosphere (left), and two collages visualizing the problematic situations in the story (right). 


\section{Visit 2: Team Cohesion and Problem Definition}

During the first co-design session, approximately two weeks after the introduction, the facilitator set out the conditions under which children would collaborate with their peers (Step 3: Scaffolding Collaboration). With the help of the teacher, children were first divided in teams of four to six boys and girls, and each team got its own place in the room to create physical boundaries between teams (SIT1C). Then, the facilitator introduced a fictional story to contextualise the design theme (SIT1a). The story described instances of children excluding and bullying one another, which were inspired by the results of children's sensitizing assignments. After having discussed the story with the children, the facilitator explained that each team would define their own unique focus and that teams would compete against each other. A peer jury would choose the winning team at the end of the last session (SIT1a). During final presentations, teams would not only have to present their designs but also their process and, therefore, they were asked to document all important design decisions (e.g. design problem, selected ideas) (SIT1a).

Afterwards, the facilitator reiterated the different steps of the design process and talked about the types of interactions and interpersonal and small-group skills (SIT4) that are required for productive collaboration. This discussion about skills was used as a stepping-stone to introduce the different roles and responsibilities that team members had to assign among them (SIT1b). The responsibilities of each role were summarized on a badge that children had to ware during the design activities. For instance, the Inspiration General had to ensure that each team member had an equal chance to contribute and that no one would impose their ideas, and the Material Guard was responsible for allocating and taking care of the materials. Giving team members distinctive roles was done to increase feelings of responsibility for doing their share of the work. The facilitator furthermore limited the amount of materials per team (e.g. one pair of scissors and one glue gun) and explained that, instead of making individual decisions, children had to discuss their approach and divide the materials accordingly. The Material Guard of each team was responsible for orchestrating this process. Finally, to allow children to practice the roles and skills as well as to strengthen team cohesion (SIT1c), the facilitator initiated an introductory design activity. For this activity, teams had to come up with a group name and design a logo, which they presented to the other teams.

In the next step (Step 4: Defining a Design Goal), teams would define their unique point of view, entailing a first convergence phase. As a warm up, teams first discussed the results of the sensitizing assignments. Then, they visualised the problematic situations in the story with a collage and, afterwards, highlighted two situations for which they would develop a solution (see Figure 4 - right). The design theme embedded in the story (i.e., preventing bullying in the social context of the class) was deliberately kept broad to leave room for interpretation. Allowing teams to define their own design goal was expected to result in feelings of problem ownership and, hence, strengthen outcome interdependence (SIT1a). Different materials were provided to make the collage (e.g., coloured paper, pictures, glue gun), and when teams were ready, they presented their design problems to the other teams and the facilitator.

For the final step of the first co-design session (Step 5: Reflection on Collaboration), children reflected on the collaboration with their team members (SIT5). They thought of three actions that were helpful, and one action that could be added or changed in the next co-design session. The goal was to diffuse tensions between team members, if any, and to improve the collaboration in the next session.

\section{Visit 3: Problem Solving and Peer Jury}

During the second co-design session, approximately one week after the first session, the facilitator first explained the goal of the session and, then, allowed children to switch roles and responsibilities with their team members. Afterwards the facilitator introduced the next divergent phase (Step 6: Ideation) by explaining the concept of brainstorming and the brainstorm rules (i.e., go for quantity, build on each other's ideas, defer judgment, say all ideas no matter how wild). With these rules in mind, teams wrote down as many ideas as 
possible on sticky notes to solve the problematic situations they had defined in the previous session. After several brainstorm rounds, teams moved to the next convergent phase (Step 7: Grouping and Selection) by grouping similar ideas together and selecting two ideas for further elaboration through sticky dot voting whereby each member could cast two votes. For the next step (Step 8: Elaboration through Making) teams were asked to further develop the selected ideas and add sufficient detail. To this end they received a bag of paper prototyping materials (e.g. scissors, cardboard, glue gun, Styrofoam, aluminium dishes, etc.) (see Figure 5 - left). The expectation was that the creative act of making things would be engaging for children and enable them to elaborate their selected ideas.

During the next convergent phase (Step 9: Presentation and Peer Jury) teams took turns to present their paper prototype and talk about their process highlights while the other teams functioned as a peer jury. Between presentations, jury members filled out a form with questions such as: "What do you like about the design?" "Why do you like it?", "If there is one thing you could change, what would it be?" and "Why would you like to change it?" (see Figure 5 - right). The feedback was discussed with the presenting team before continuing with the next presentation. Children knew beforehand that they would have to present their prototype to create a sense of individual accountability (SIT3). Afterwards, in the final step (Step 10: Iteration or Wrap Up), teams reflected on the design and collaboration process, and the facilitator explained what would happen with their ideas. The facilitator wrapped up the session by handing out design certificates to reward children for their efforts.
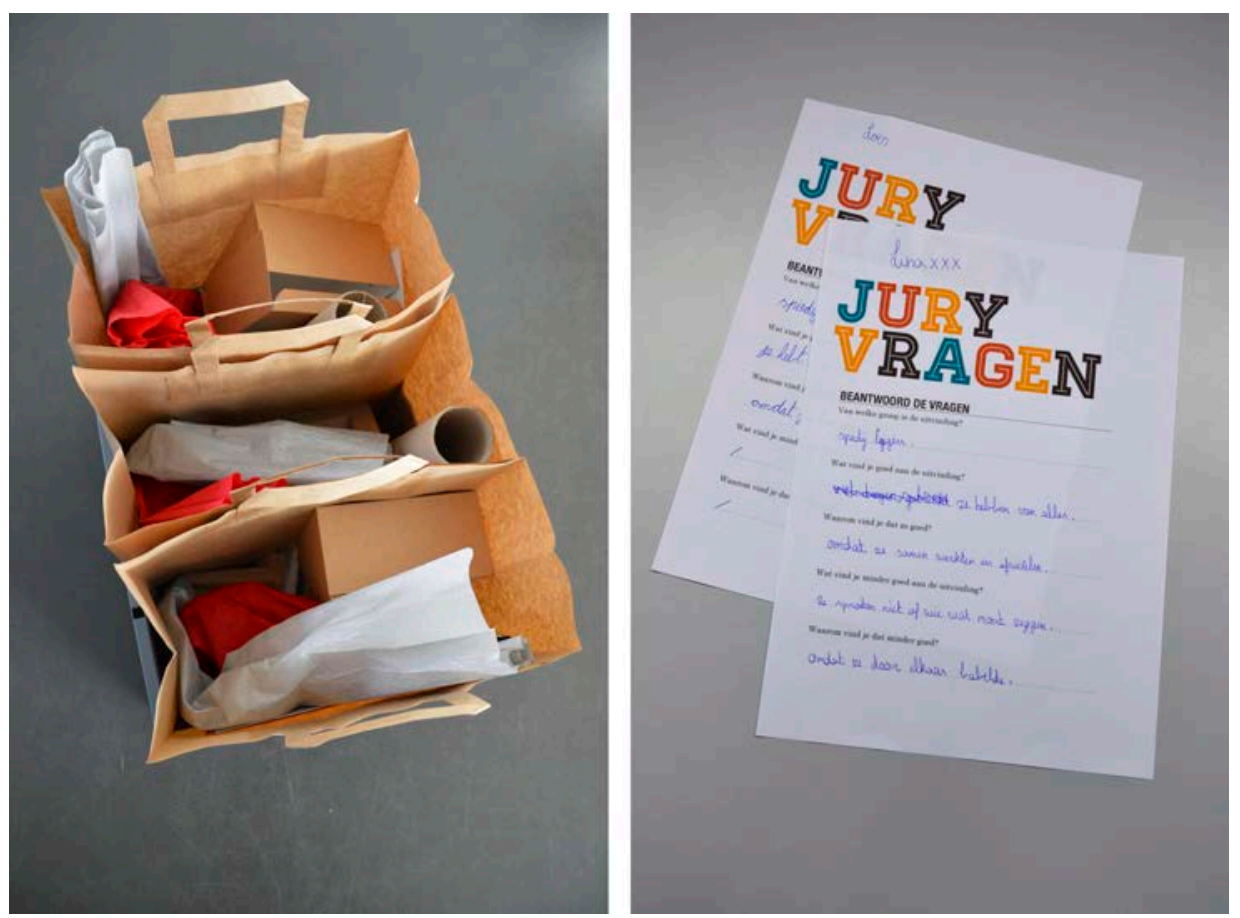

Figure 5: Bags with paper prototyping materials to develop the selected ideas (left), and two completed jury forms (right).

\section{Reflection on the co-design process}

CoDeT integrates DT and SIT to scaffold children's creative abilities and collaboration in co-design activities characterised by high child-to-adult ratios. On the whole, applying CoDeT in a case study involving 49 children between the ages of 9 and 10 in two schools yielded positive results, but areas for improvement could be identified as discussed below. These insights were used to improve the CoDeT approach (see section 4). 


\section{Step 1: Introduction}

The reactions on the design theme of preventing bullying were varied, ranging from enthusiastic to wait-andsee attitudes. Some children immediately asked questions about the design theme, whereas others did not join the discussion. A similar situation occurred when the facilitator explained the different steps of the design process and the required skills (SIT4) to collaborate in a team. Although some children understood the importance of separating the divergence and convergence of ideas, for others this explanation was too abstract without first hand experiences. Hence, the facilitator reiterated the explanation about the design process and the required skills during the first co-design session (i.e., the second visit), which helped children to gradually immerse themselves in the design theme and organize their teamwork. However, during the second session (i.e., the third visit) this explanation was not reiterated which led to confusion about how the different steps were interlinked. For most children, learning to separate divergence and convergence was a gradual process that required iteration and sustained reflection.

\section{Step 2: Sensitizing}

The individual sensitizing assignments prior to the team activities encouraged children to reflect on the design theme through hands-on activities, creating a divergent mind-set and allowing time for incubation. During the first co-design session, most children were eager to show and discuss the results of the assignments with their team members, which resulted in lively conversations about what constitutes a bad class atmosphere (see first sensitizing assignment). This way, a cold start for the team activities was avoided.

\section{Step 3: Scaffolding Collaboration}

In this step, optimal conditions were created for children to collaborate with their team members. This was achieved by implementing three types of positive interdependence: outcome (SIT1a), means (SIT1b) and boundary (SIT1C) interdependence.

Outcome interdependence (SIT1a) was implemented by reiterating the design theme and explaining that teams would compete against each other. A few questions aside about how the winning team would be identified, this part was easy to comprehend for children. This was less so for the facilitator's request for teams to document their progress towards their design goal, because children were not yet aware of all the design decisions they would have to make in the next steps. Providing booklets or design diaries with clues about how and when to document their design process could have helped teams to overcome this obstacle.

Implementing boundary interdependence (SIT1C) by giving each team a private workspace to set physical boundaries was not always possible due to practical constraints. In most schools, the different teams had to be seated in a rather small room, which led to an exchange of ideas across teams. In addition, not all children were happy when they were first divided into teams. However, the introductory design activities in which teams designed a team logo were often effective in reversing feelings of initial disappointment. Although some teams struggled to collaborate successfully at first, a positive evolution was observed in children's commitment towards their team.

Implementing means interdependence (SIT1b) was a process of trial and error. In the first session, role division led to disagreements because it was not emphasized that team members had to negotiate which role was best suited for which team member. On top of that, the responsibility that came with each of these roles was not always clear. This problem was solved in the second session by providing better instructions, summarizing the responsibility for each role on badges that children had to wear, and providing active tasks for each role throughout the session. For instance, Timekeepers had to set an alarm clock and Material Guards received a 
bag with prototyping materials. This encouraged children to fulfil their role and responsibility in the team, while limiting the possibility that some children would not contribute (i.e., Free Riding ${ }^{1}$ ).

Limiting the amount of materials, another way to implement means interdependence, did not always enhance communication between team members about how to approach the task, and sometimes even led to process conflicts (e.g., about who could use the pair of scissors). At first, extra materials were given to solve such disputes, but this did not enhance collaboration either. Therefore, children were encouraged to negotiate a solution themselves, which eventually resulted in more constructive dialogues. These observations suggest that limiting the amount of materials should be applied with caution, and that children need to know the underlying rationale of this technique.

\section{Step 4: Defining a Design Goal}

To reduce the possibility space for the first time since its expansion in the Sensitizing step, each team defined a unique design problem. By means of a collage, teams first visualised the story that was used to introduce the design theme and strengthen outcome interdependence (SIT1a). Afterwards each team selected two situations, explaining what makes these situations problematic and worth solving. This storytelling approach had a positive impact on children's engagement with the design theme, and many children sympathized with the story's lively examples. The story was also easily remembered and provided focus during the different activities, also beyond the Defining a Design Goal step, as was demonstrated by children who spontaneously reiterated the story. Some exceptions notwithstanding, most teams were committed to solve the problems they had defined based on their interpretation of the story, which indicated feelings of problem ownership. This was less so in previous work by the authors where the design problem was defined upfront and children frequently got caught up in an unserious and disruptive atmosphere (i.e., Laughing Out Loud ${ }^{2}$ ) (Van Mechelen et al., 2015, 2014a).

\section{Step 5: Reflection on Collaboration}

In this step at the end of the first co-design session (i.e., the second visit), children reflected on how they could improve their collaboration (SIT5), which yielded positive results in the next session. However, this step was not without problems either because children blamed each other for things that went wrong, which sometimes led to further escalations. As a response to this problem, personal attacks were no longer allowed, and teams first had to focus on actions that had been helpful and, afterwards, think about one individual action to improve the teamwork. An important lesson is that the purpose of group processing needs to be emphasized upfront: to improve the group process over time through self-analysis and not to evaluate team members. All together, these small interventions eventually resulted in more promotive interactions between team members.

\section{Step 6: Ideation}

The next divergent phase entailed a brainstorm activity whereby teams wrote as many ideas as possible on sticky notes. Despite the fact that children seemed to understand the purpose of brainstorming and the different brainstorm rules, putting this knowledge into practice was not an easy task. Some children got stuck in right or wrong thinking during brainstorming or were reluctant to share the ideas they had written down with their team members. In a few teams, the facilitator had to interrupt the process to reiterate the purpose of the brainstorm rules. These short interventions were usually sufficient to improve the flow of the ideation process,

\footnotetext{
${ }^{1}$ Free Riding: Children who devote less effort and who do not contribute substantially to the achievement of the group goals (Van Mechelen et al, 2015).

2 Laughing Out Loud: An unwillingness of some children to take the design task at hand seriously, resulting in a disruptive atmosphere in the team (Van Mechelen et al, 2015).
} 
but a more efficient strategy would have been to include a practice round before teams started brainstorming solutions for their design problem. This practice round should include a short discussion about children's experiences with applying the brainstorm rules.

\section{Step 7: Grouping and Selection}

After generating multiple ideas to solve the design problem, in the next convergent phase teams were asked to group similar ideas and, afterwards, to select two ideas for further elaboration (Step 7 Grouping \& Selection). Ideas were selected through sticky dot voting whereby each member had two votes. The selection procedure did not go completely as planned, because some teams forgot to cluster similar ideas, which slowed down the voting process because children were overwhelmed with the quantity of ideas to choose from. Another issue was that children had the tendency to vote for their own ideas or for ideas promoted by fellow team members. Consequently, ideas were not always evaluated based on their inherent quality to solve the design problem but, rather, on subjective measures or as a result of peer pressure exerted by team members (i.e., Unequal Power ${ }^{3}$ ). In an attempt to deal with this issue, the facilitator instructed children to give no more than one vote to one of their own ideas. However, a more efficient way could have been to ask teams to define requirements upfront (e.g. a list with needs and wishes) to evaluate ideas more objectively.

\section{Step 8: Elaboration through Making}

In the next divergent phase (Step 8 Elaboration through Making) teams built a paper prototype inspired by the selected ideas. Most teams started building right away whereas other teams needed more time to figure out how to combine or reconfigure the selected ideas, which was sometimes done quite literally (e.g. as two separate functionalities). In most cases, the bag with paper prototyping materials was sufficient for teams to build what they had in mind, and in other cases teams spontaneously exchanged materials with one another. While teams were building the prototype, some questions were raised about whether a prototype can be a scaled model and to what extent it should actually work. The facilitator explained that the act of making helps to elaborate the selected ideas because additional details have to be considered, and that the main purpose of paper prototyping is to visualise the design solution in order to communicate it more effectively. This explanation reassured teams that they were on the right track but should have been given beforehand.

\section{Step 9: Presentation and Peer Jury}

To create a sense of individual accountability (SIT3), a peer jury was installed at the end of the second codesign session (i.e., the third visit). This proved to be an effective strategy, because children wanted to make a good impression in front of their classmates. Unfortunately, most teams focused exclusively on their final design and did not include any process highlights (e.g. role division, important design decisions) in their presentations. As suggested earlier, a booklet or design diary in which teams document their design process could prevent this.

When a team finished their presentation, the other teams filled out a jury report to provide feedback. Answering the questions on the jury form was not an easy task. It was especially difficult for children to explain why they liked or disliked a design. Despite this difficulty, the questions triggered reflection and resulted in substantive discussions about the presenting team's design. An idea to improve the jury form is to add more finegrained criteria to evaluate the design (e.g. with respect to the quality of the solution, the look and feel) and a score-box per item. By adding a different score per item, a winning team could be identified in a more objective and transparent manner.

\footnotetext{
3 Unequal Power: Children with a higher social status than others, who exert significant influence on the group process, either positively or negatively (Van Mechelen et al, 2015).
} 


\section{Step 10: Iteration or Wrap Up}

In this project, teams went through one DT cycle meaning that the project was wrapped up after handing out design certificates at the end of the presentations. If time allows, teams could go through multiple DT cycles, evaluating and reframing their initial design problem, generating additional ideas, and adapting their prototype accordingly. A selection of feedback received from their peers and/or the facilitator could be the starting point for a new DT cycle.

\section{Role of the facilitator}

During the co-design activities, the role of the facilitator was that of a guide on the side who explained the different steps and monitored children's collaboration. During an introductory meeting, the teacher explained that most children were not accustomed to working in a team, which was noticeable during the co-design activities. Especially in the beginning, quite some children followed their idiosyncratic interests without consulting fellow team members, which sometimes resulted in disputes (i.e., Dysfunctional Conflict ${ }^{4}$ ). Whereas some friction can help teams to think beyond the ordinary, children should at least discuss their ideas and argue for their point of view. The role of the facilitator was vital here: specifying the types of interactions (SIT2) children should engage in (e.g., active listening, providing arguments), and pointing towards children's roles and responsibilities in the team (SIT1b). This had a positive impact on how children interacted with each other. To further improve this process, a discussion etiquette could be agreed on together with the children at the start of the first session (e.g. in Step 3: Scaffolding Collaboration). This etiquette could serve as a visual reminder for the interpersonal and small group skills (SIT4) required for productive collaboration.

\section{CoDeT: COLLABORATIVE DESIGN THINKING}

The CoDeT (Collaborative Design Thinking) approach enables design researchers to organise and conduct codesign sessions at high child-to-adult ratios (ca. 1 adult for 15 to 20 children) (see Figure 6). The approach has a dual goal: scaffolding design thinking and facilitating effective collaboration between children. The next paragraphs describe the revised CoDeT approach in a direct hands-on manner. First, the decisions that have to be made upfront are discussed, next three general guidelines for facilitators are presented, and, finally, each step of the approach is explained in a what-why-how structure. The what-section explains the step, the why-section its relevance, and the how-section suggests techniques and tools that can be used for this step.

Although this section presents a revised version of CoDeT that incorporates the insights of the case study, the underlying theoretical framework remains intact (see Figure 3). All changes are to be found in procedural details as noted in the previous section.

\section{Before the Start}

To apply the CoDeT approach, a number of decisions have to be made regarding the design theme, the age group, and the location for the co-design activities:

- Design theme: a broad theme is preferred over a narrowly defined problem. This way, children can co-determine the direction and outcome of the design project.

- $\quad$ Age group: the CoDeT approach was developed for 9- to 10-year olds, but may also be suitable for slightly younger and older age groups.

- Location: the approach is especially useful for co-design settings with high child-to-adult ratios (i.e., 1 adult for 15 to 20 children), such as in schools, museums and maker spaces.

\footnotetext{
${ }^{4}$ Dysfunctional Conflict: Different types of conflicts may occur between children, including task-oriented conflicts about what should be done, and process-oriented conflicts about how it should be done (Van Mechelen et al, 2015).
} 


\section{THE CODeT PROCEDURE}

- Start/End or Iteration

- Divergence

- Convergence

+ Improving collaboration

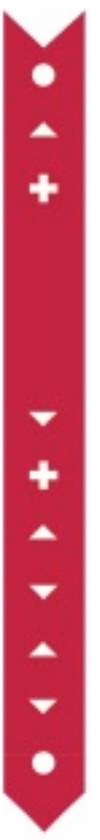

I. Introduction

2. Sensitizing

3. Scaffolding Collaboration

Outcome Interdependence

Means Interdependence

Boundary Interdependence

4. Defining a Design Goal

5. Reflection on Collaboration

6. Ideation

7. Grouping and Selection

8. Elaboration through Making

9. Presentation \& Peer Jury

10. Iteration or Wrap up

Figure 6: The different steps of the CoDeT (Collaborative Design Thinking) approach. The ten steps constitute one design cycle that can be iterated multiple times: steps 2, 6 and 8 are divergent, steps 4,7 and 9 are convergent, and steps 3 and 5 focus on collaboration.

Once these decisions have been made, the different steps of the CoDeT approach have to be prepared. For each of these steps, a combination of different techniques can be used (see how-sections). The different steps are: (1) Introduction, (2) Sensitizing, (3) Scaffolding collaboration, (4) Defining a point of view, (5) Group processing, (6) Ideation, (7) Grouping and Selection, (8) Elaboration through Making, (9) Presentation and Peer Jury, and (10) Iteration or Wrap up (see Figure 6). Before explaining the steps in more detail, two important guidelines for facilitators are presented.

\section{Guidelines for Facilitators}

\section{Adapt to the Context}

Have an introductory meeting with those responsible for the location where the co-design activities will be organised (e.g. teacher or school staff) to gain insight in the contextual specificities (e.g. classroom and class culture), and adapt CoDeT accordingly. CoDeT can be executed as a whole day session, or divided over multiple sessions in two or more days. In the latter case, close each session with Reflection on Collaboration (see Step 5), in order for teams to improve their collaboration in the next session. Different techniques and tools are suggested for each step but, as long as no step is left out, alternatives can be developed and used. When running the sessions, on the spot adjustments will be needed which requires a flexible attitude from the facilitator. Keep in mind that CoDeT is a means and not a goal in itself.

\section{Encourage Promotive Interactions}

Have a conversation with the children about the kind of interactions that are required to collaborate productively, such as turn taking and active listening (e.g., during Step 3), and encourage these interactions during the co-design activities. When one or more children do not collaborate well (i.e., Free Riding ${ }^{1}$ ), emphasize the quality of their earlier contributions, if possible, and/or gently point them towards their unique role and 
responsibility in the team. When conflicts occur, have an open conversation and ask children to come up with a solution before suggesting one. Bear in mind that conflict is not necessarily a negative force. A moderate amount of friction can be useful to avoid Groupthink ${ }^{5}$, because more energy is created when sharing diverse viewpoints. Allow for such friction but emphasize that children should provide arguments for their opinion.

\section{Steps CoDeT}

\section{Step 1: Introduction}

Have a dialogue about what designers do and why. Afterwards, introduce the design theme and why children's help is needed. Give a quick overview of the co-design activities, and clarify what will be done with children's input afterwards. A useful tool to prepare this initial introduction is the CHECk tool (Read et al., 2013; Van Mechelen et al., 2014b).

\section{Step 2: Sensitizing}

\section{What?}

Triggering children's reflection about the design theme to prepare them for the co-design activities. This can be done individually and/or as an initial group activity.

\section{Why?}

The goal of the sensitizing step is to stimulate children's curiosity about the design theme, and to create a divergent mind-set. Through one or more hands-on tasks, children are encouraged to reflect on the design theme and deepen their understanding of the problematic situation, either individually and/or as an initial group activity. These preparatory tasks give room for thought on how the design theme can be addressed. In addition, this creates a desire to know more about the design theme, and increases feelings of problem ownership. In the sensitizing step, the possibility space expands for the first time (divergence), meaning that a wide range of options and directions are considered for further investigation.

\section{How? Examples}

Different techniques and assignments can be used to sensitize children. Examples include visualizing the design theme with a drawing, interviewing or observing peers and other stakeholders, gathering existing information about the problematic situation, and keeping track of relevant experiences and thoughts in a userdiary. It is advisable to make these tasks hands-on, playful and creative, and to add an element of surprise to keep children engaged (e.g., putting assignments in sealed envelopes and including a small gift). It is important to make clear arrangements about how and when to collect the results. One possible procedure is to give children individual assignments which they do at home in their own time, collect the results one week later, and use these as input for the co-design activities (e.g., a team discussion).

\section{Step 3: Scaffolding Collaboration}

To scaffold collaboration, a situation is created in which children perceive that they have to work together to accomplish a shared design goal, and that individual efforts are important for the entire team. This situation whereby children need each other to attain the goal is referred to as positive interdependence. In contrast, when children are competitively linked, the goal attainment of one team (e.g., winning the prize for best design idea) will result in failure for the other teams. This is referred to as negative interdependence. Negative interdependence should be aimed for between teams (inter group) and positive interdependence within

\footnotetext{
${ }^{5}$ Groupthink: An emphasis on concurrence seeking, which leads to poor decision-making because valuable choice alternatives are neglected (Van Mechelen et al, 2015).
} 
teams (intra group). There are three complementary types of positive interdependence: outcome, means and boundary interdependence (Johnson and Johnson, 2005). By implementing all three types in co-design activities, children will be encouraged to collaborate productively and in mutual respect for one another. The suggested techniques for the three types of interdependence can be used interchangeably.

\section{Outcome Interdependence}

\section{What?}

Children experience outcome interdependence when they share one or more design goals and when they perceive that working together will improve their chances to attain these goals.

\section{Why?}

When outcome interdependence is structured adequately, a situation is created in which team members can only achieve their goals if the group as a whole succeeds. These goals can either be defined top-down or through negotiation. If design researchers decide on the goals beforehand, these should relate to children's experiences in order to be meaningful. A better way is to involve children in defining the direction and the outcome of the co-design process (see Step 3 Defining a Design Goal). This will increase feelings of problem ownership, task cohesion and a willingness to achieve the goals, which helps to prevent challenging group dynamics such as Laughing Out Loud ${ }^{2}$. Outcome interdependence motivates children to take responsibility and encourage other team members to do the same.

\section{How? Examples}

\section{Storytelling to Present the Design Theme}

A first way to implement outcome interdependence is through storytelling. Write a short story, either fictional or real, to contextualize the design theme with lively, detailed examples, and read it out loud at the start of the co-design activities. This story functions as the anchoring event throughout the activities. Depending on the project, the design theme embedded in the story can deliberately be kept open to leave room for problem finding. Teams can define a problem based on their interpretation of the story (see Step 3 Defining a Design Goal), for which they iteratively develop a solution in the next steps.

Documenting the Design and Collaboration Process

Hand out design diaries, one for each team (see Means Interdependence for composing teams), in which children document their process, ranging from the initial exploration of the problem space to the eventual solution. This encourages children to reflect on the process and discuss it with their team members (e.g., their experiences, important design decisions). Teams can furthermore use this documentation to prepare the presentation of their design at the end of the co-design activities. For instance, they can explain which decisions were made along the way and for what reasons (see Step 9 Presentation and Peer Jury).

Individual and Team Incentives

Combine individual incentives with team incentives. Explain which incentives will be handed out at the end of the co-design activities, and under what conditions. Providing incentives for doing well as a team can strengthen children's willingness to collaborate. For instance, children can receive an individual design certificate or any other tangible reward after successfully running through the different steps with their team. In addition, a winning team can be chosen based on the results of the Peer Jury at the end of the co-design activities (see also Boundary Interdependence and Step 9 Presentation and Peer Jury). 


\section{Means Interdependence}

\section{What?}

Children experience means interdependence when they depend on one another for resources and abilities to achieve the shared goals.

\section{Why?}

Structuring means interdependence can enhance communication and overall collaboration between team members, because children have complementary skills, distinct roles, and/or have to share a limited amount of resources. When children need each other to achieve a shared goal, they often feel more responsible for contributing to the teamwork. Hence, implementing means interdependence can prevent and mitigate challenging group dynamics such as Unequal Power ${ }^{3}$ and Free Riding ${ }^{1}$.

\section{How? Examples}

Small, Heterogeneous Teams

Compose small heterogeneous teams in which four to six children with different skills work together (e.g. verbal, creative, motor, analytical skills). Dividing children into teams is best done with the help of the teacher who is better aware of the social dynamics in the class group, and the strengths of each child.

\section{Different Roles and Responsibilities}

Initiate a short class conversation about effective collaboration and good communication, and, afterwards, discuss the different roles and responsibilities that team members have to divide among each other. These roles can be conceptual in nature (e.g., looking through someone else's eyes) or practical (e.g., time keeping). At least one of these roles should focus on good communication (the Communication Soldier). This role can be linked to a discussion etiquette that children come up with during a class discussion, and that includes tips for turn-taking, good questioning and arguing for an opinion. Other examples of roles are taking care of the materials (the Material Guard), keeping track of the time (the Timekeeper), and completing the team's design diary (the Diary Major). Children should not choose these roles randomly, but either come up with the roles themselves or, when they are top-down defined, negotiate which role is best suited for which team member. The responsibility that comes with each role has to be clearly communicated (e.g., by detailing each role on a badge), and children need time to practice the roles before initiating complex design tasks.

\section{Limiting Materials}

Limit the amount of some materials per team (e.g. one pair of scissors or glue gun per team), but do so wisely. The idea is that, by limiting some of the materials, teams have to discuss their approach upfront and divide the tasks and materials carefully. This rationale should be explained at the start, if not, the technique can have the opposite effect and result in process conflicts, hampering rather than strengthening the team's collaboration. To guarantee that all team members can contribute equally to the design process, it is advisable to make someone in the team responsible for the division of materials (the Material Guard).

\section{Boundary Interdependence}

What?

Children experience boundary interdependence when they share a team identity, and when they are intrinsically motivated to help one another succeed. 


\section{Why?}

Boundary interdependence improves the social cohesion of a team, because the team members experience a shared identity. When children identify with each other, they may be more willing to help each other in achieving the design goal, and not merely because it is in their own interest to do so. Especially heterogeneous teams with a large variety in terms of skills and backgrounds benefit from creating a shared identity. Teams that lack social cohesion easily fall victim to challenging group dynamics such as Apart Together ${ }^{6}$ and Dysfunctional Conflict ${ }^{4}$.

\section{How? Examples}

Proximity and Inter-group Competitive Mechanisms

Create physical boundaries between the in- and out-group by spatially separating the teams. Then use intergroup competitive mechanisms to further strengthen these boundaries. Explain that a winning design will be chosen at the end of the co-design activities, which means that teams will compete against each other (see Step 9 Presentation and Peer Jury). When using such inter-group competitive mechanisms, it is important that all children perceive that they accomplished something (e.g., by handing out individual design certificates) and not only the children of the winning team.

\section{Creating a Shared Identity through Team Building}

Use all kinds of team building activities to improve social cohesion and commitment towards the team. This is especially useful to reverse feelings of disappointment when children are assigned to a team they did not prefer. Team building activities furthermore allow children to get used to their role as designers. One such activity is to think of a team name and a slogan, and to design a logo. Before moving on to the next step, each team briefly presents their logo to the other teams to which they are competitively linked.

\section{Step 4: Defining a Design Goal}

\section{What?}

Teams define a point of view that determines the future focus of the co-design activities, relying on the insights from the sensitizing assignments introduced in Step 2.

\section{Why?}

The point of view reflects the co-design team's perspective on the design theme. Whereas the design theme is usually defined top-down by the project, in this step, children reinterpret it and make it their own. Each team synthesizes the insights from the sensitizing process (e.g., through a group discussion), resulting in a concrete problem statement and a list of criteria that should be met to solve the problem. This determines the future focus and may lead to feelings of problem ownership, which further strengthens outcome interdependence among the team members. Defining the design goal is a first convergence phase that drastically reduces the possibility space.

\section{How? Examples}

\section{Problem Statement and Requirements}

First teams discuss (some of) the results of the individual sensitizing assignments in which they explored the design theme. Then, teams read the story that contextualises the design theme (see Outcome Interdependence), and define a problem statement (one per team) in the form of a "How could we..." question based on

\footnotetext{
${ }^{6}$ Apart Together: Children who work individually and hold on to their own interests and ideas instead of negotiating a solution with their fellow team members (Van Mechelen et al, 2015).
} 
their interpretation of the story. While defining a problem statement, teams have to think about why it is worth solving. Probing for why-questions stimulates reflection and may reveal children's underlying motives for their choice. Finally, teams think of different requirements that should be met to solve the problem (e.g., a list of needs and wishes), and they write the problem statement, motivation, and criteria in their design diary.

\section{Visualization of the Design Theme}

Each team visualises their problem statement with a drawing or a collage. To execute this task, each team receives a bag with arts and crafts materials. When teams are ready, they show their visualization and explain their problem statement to the other teams. Additionally, they provide their motivation for addressing that problem, and their criteria for a solution. The other teams can ask questions and provide constructive feedback. An alternative is to first visualise the story or a particular moment in the story, and only afterwards define a problem statement and criteria. This way, visualizing the story and its embedded design theme becomes a tool for interpretation rather than communication.

\section{Step 5: Reflection on Collaboration}

\section{What?}

Teams reflect on the group process and make decisions about which actions to continue or change in the remaining co-design activities to improve the collaboration.

\section{Why?}

Children are often not used to working in a team, and sometimes lack interpersonal and small-group skills to deal with differing voices, which can result in challenging group dynamics such as Dysfunctional Conflict ${ }^{4}$. To continuously improve collaboration over time, children have to reflect on their actions. This reflective process deepens their understanding about effective collaboration and good communication, and how it can be improved. Group processing has a positive impact on children's interpersonal and small-group skills, and the motivation to use these skills. It furthermore increases feelings of commitment and responsibility towards the team.

\section{How? Examples}

Initiate this step halfway the co-design activities. Explain that personal attacks are not allowed, and that children should focus on how they can improve the collaboration instead of blaming each other. For instance, let children think of three actions that were helpful and one action that each member can do that to improve collaboration. When children have different roles and responsibilities in the team, let them reflect on how well they executed their role and what they could do differently next time. This will increase the likelihood for constructive dialogues. When teams have to come to an agreement about how to improve their work, ask them to write a short summary in the design diary. Before moving on to the next step, briefly discuss what children have learned so far about productive collaboration and good communication (see also Means Interdependence). If necessary, alter the discussion etiquette based on the outcomes of this conversation.

\section{Step 6: Ideation}

What?

Teams generate a wide range of ideas to address the design problem, which they defined in Step 4.

\section{Why?}

Separating divergence and convergence of ideas is considered good practice for creative thinking. Therefore, a wide range of ideas is generated before evaluating these ideas. During ideation, the possibility space expands 
to its maximum. Ideas rarely come out of nowhere and are often based on a recombination of previous insights and experiences. It is therefore important that team members build on each other's ideas during brainstorming, turning it into an open and social process.

\section{How? Examples}

Introduce the divergent thinking technique (e.g., brainwriting, superhero brainstorming, gamestorming) that teams will use to generate a broad variety of ideas in a relatively short amount of time, and explain the rules for ideation. Examples of such rules can be found in Osborn's (1953) brainstorming technique: "do not criticize", "quantity is wanted", "combine and improve suggested ideas", and "say all ideas that come to mind no matter how wild". Other rules that can be added are "be visual" and "stay focused on topic". Start with a warm-up exercise, and alter between individual thought (e.g., individual brainstorm) and building on each other's ideas (e.g., passing on written ideas to inspire each other).

\section{Step 7: Grouping and Selection}

What?

Teams group similar ideas together and, afterwards, select a limited number of ideas for further development.

\section{Why?}

After generating a wide range of ideas in the previous step, the possibility space drastically reduces during Grouping and Selection. Ideas are selected based on their inherent quality to solve the design problem, and not merely on personal preferences. Special attention is needed to safeguard original ideas. Due to their novelty, it is difficult to predict whether these ideas will work (i.e., solve the design problem), which makes them both risky and vulnerable for early elimination. This possibility of early elimination is amplified in teams that are prone to Groupthink ${ }^{5}$.

\section{How? Examples}

Teams group similar ideas together, and then evaluate the ideas based on the requirements (i.e., list with needs and wishes) defined in the Step 4. To preserve unusual ideas, teams can add the requirements' originality or novelty to their list if they did not include it already. The idea that addresses most requirements is selected. In case multiple ideas meet a similar number of requirements, each team member can vote for his or her favourite idea (e.g., through sticky dot voting) and the idea with most votes is taken to the next step. An alternative strategy is to select up to three ideas after the requirements evaluation, and either merge these ideas or build one prototype per idea in Step 7 Elaboration through Making.

\section{Step 7: Elaboration through Making}

\section{What?}

Teams synthesize the selected ideas and further develop these ideas into one or more visual representations or prototypes.

\section{Why?}

In the Elaboration through Making step, teams synthesize and develop the selected ideas into one or more design concepts. These concepts solve the problematic situation defined in the Step 4, or at least improve that situation. In order to develop the concepts, new details and alternatives are to be considered, meaning that the possibility space opens up again. Elaboration is a hands-on process in which teams create visual representations of their concepts with low-tech or paper prototyping materials. The act of making stimulates reflection and helps to identify areas that need additional thought or specification. 


\section{How? Examples}

Teams synthesize the selected ideas and plan what kind of prototypes they are going to build (e.g., scaled 3D model, photo story, role-play or video). After building the prototypes, they choose the most promising one based on the criteria defined in Step 4, and further refine it. When time is limited, teams can stick to one prototype. Before teams start building, explain that synthesizing ideas can result in a new idea, in analogy with mixing two colours into a new one (e.g., mixing red and blue results in purple). Using such visual metaphors improves children's understanding of the design process and the importance of separating divergence and convergence. When teams are finished, they should think of a title and tagline for their selected prototype, which they write down in the design diary. To build the prototypes, teams receive a bag with low-tech or paper prototyping materials (e.g., scissors, cardboard, aluminium dishes, ropes, coloured paper, glue gun).

\section{Step 8: Presentation and Peer Jury}

\section{What?}

Teams present their design problem and final prototype to their peers and the adult facilitator who can ask questions and provide constructive feedback.

\section{Why?}

In this step, teams present or demonstrate their prototype to the other teams to gather feedback. In most cases, the other teams represent the envisioned users of the prototype, which makes their feedback especially valuable. The facilitator moderates the discussions and asks open-ended questions to clarify important design decisions. Teams can use the feedback to revise their prototype and, if necessary, reconsider earlier made design decisions. Teams can go through multiple cycles of selecting feedback (convergence) and making adjustments (divergence) depending on the available time. A peer jury creates a sense of accountability, because the team is held responsible for achieving a shared design goal. Feelings of accountability strengthen outcome interdependence, and can mitigate challenging group dynamics such as Apart Together ${ }^{6}$.

\section{How? Examples}

Presentation

Teams prepare a presentation about their selected prototype. Instruct teams to write a short summary in the design diary, including the title and tagline of the prototype (see Step 7 Elaboration through Making), the major strengths of the solution, and how it addresses the design problem and requirements (see Step 4 Defining a Design Goal). In addition, ask teams to consult their design diary to select a few process highlights (e.g. outcome of Step 5 Reflection on Collaboration, key design decisions) and include these in their presentation.

Peer Jury

When one team is presenting their prototype, the other teams form the jury. They have to listen carefully, ask clarifying questions and provide constructive feedback. Afterwards, each jury team gives scores for predefined criteria (e.g., quality of the concept, look and feel, presentation), and provides arguments for these scores. One way of doing this is to provide forms (one for each team) with questions such as "Does the design solve the problem defined by the team? Why or why not?" and "What do you like about the look and feel of the design? What would you like to change?". These questions stimulate discussion among the jury members, and the answers provide insight in how teams value each other's designs. After jurying, the winning team is identified by adding up the individual scores (see Boundary Interdependence). The winning team receives a tangible reward (e.g. a design cup), and all children receive a design certificate for their achievements. 


\section{Step 9: Wrap Up}

Explain what will happen with children's ideas, and if and how they will be involved in the next phase of the design process. Regardless of whether children have a role in the next phase, they should be debriefed about the results of the analysis. A recommended method to interpret co-design outcomes is GLID (Grounding, Listing, Interpreting, Distilling) developed by Van Mechelen and colleagues (Van Mechelen et al., 2017). Finally, have a conversation with children about their experiences with teamwork and designing. The outcomes of Step 5 Reflection on Collaboration can be used as a point for this conversation.

\section{DISCUSSION}

When co-designing technology with children, children may team up with design researchers or they may collaborate with peers while design researchers take on a facilitating role. The latter is a useful strategy for high child-to-adult ratios (ca. 1 adult for 15 to 20 children) such as in the case study presented in this paper. An important advantage of co-design sessions at high child-to-adult ratios is that a broad variety of children and, hence, perspectives, can be included in the design process, guided by only one or two design researchers. This lends itself to what Read and colleagues (2014) have referred to as a representative democracy perspective of PD whereby child participants represent a multiplicity of childhoods, each with their own power, status, social and economic differentials (Dawes, 2000).

To reap the benefits of co-design, here conceptualised as a form of collaborative creativity, it is required that multiple actors work together towards one or more design goals. However, previous work by the authors has shown that children often lack a basic understanding of the design process and that productive collaboration can be hard to achieve, especially when children lack motivation and/or skills to work in a team setting. This is further complicated in co-design settings with high child-to-adult ratios because only few adults facilitate collaboration (Van Mechelen et al., 2015b, 2014a). The CoDeT approach and its underlying theoretical framework (see Figure 3), which integrates DT and SIT, address these challenges and enable children to work relatively independently from adults in co-design activities.

CoDeT has two main strengths. Firstly, children alternate between steps of divergence or creating choices (Sensitizing, Ideation, Elaboration through Making) and convergence or making choices (Defining a Design Goal, Grouping and Selection, Peer jurying) to scaffold design thinking. This enables children to iteratively define and solve design problems with minimal facilitation of adults who take the role of guides on the side, a requirement for co-design settings at high child-to-adult ratios. To this end, the case study in which CoDeT was applied yielded promising results. Children experienced problem ownership and had time to reflect on and gradually emerge themselves in the design theme. This process started in the first divergence-convergence phase of CoDeT, whereby children are sensitized about the design theme and then define a unique point of view with their team. This attention for problem finding before moving on to solution finding is a unique feature of CoDeT.

Secondly, with CoDeT, challenging intragroup or co-design dynamics (e.g. Free Riding, Groupthink, Apart Together; see Van Mechelen et al., 2015b) are mitigated. By structuring outcome, means, and boundary interdependence, conditions are created for productive collaboration for children. Defining a design goal, allocating roles and responsibilities, designing a team logo are just a few examples of how children of the same team become positively interdependent. Moreover, children are encouraged to develop interpersonal and smallgroup skills, and become increasingly capable of managing differing voices with only little adult facilitation. For instance, during Reflection on Collaboration (CoDeT Step 5), children reflect on the team process and decide which actions to continue or change, which has a positive impact on their collaboration. This explicit focus on structuring positive interdependence within co-design teams and negative interdependence between teams is another unique feature of CoDeT. 
Despite these qualities, CoDeT and the case study presented in this paper have limitations that require further research. Firstly, the CoDeT approach has only been used in studies with 9- to 10-year-old children in two types of schools. As a consequence, modifications may be needed for co-design activities with different age cohorts and in different contexts. Although CoDeT is presented as a sequence of steps, the underlying theoretical framework allows for such flexibility. Design researchers can spread out the ten steps over more than three days, do multiple cycles of these steps, and/or implement them in alternative ways. The FACIT PD framework developed by Walsh and colleagues (2013) to describe co-design techniques along eight dimensions (e.g. partner experience dimension, design space dimension) can guide design researchers in developing and adapting techniques for the different steps of CoDeT. This flexibility to adapt CoDeT to different circumstances does not mean that steps should be left out, because each step links to either one of SIT's mediating principles or to one of the phases of the DT model, which together form the backbone of CoDeT (see Figure 3). Evaluating the robustness of CoDeT to better understand the required minimal and ideal conditions of the approach is a direction for future work. To this end, applications of CoDeT by other design researchers in a variety of contexts will be of great value.

Another area for further research concerns children's underlying motives to participate in co-design settings with high child-to-adult ratios (see Iversen et al., 2013). In schools, a broad variety of children can be found resulting in rich and diverse viewpoints, but a downside is that some children may lack motivation to participate in the design process, which can have a negative impact on the team efforts (Van Mechelen et al., 2014a). The question is to what extent facilitators should attempt to reverse a fundamental disinterest to participate in co-design settings characterised by high child-to-adult ratios, especially when children are obligated by their teacher to join the activities. The difficulty lies in distinguishing a fundamental disinterest from other causes, such as feelings of insecurity about one's ability to make a meaningful contribution. Gaining insight in these underlying motives can help facilitators to increase children's willingness to participate in the design process, even when their initial motivation is rather low. This may, in turn, result in what Yip and colleagues (2017) have referred to as balanced partnerships between adults and children, because facilitators have to spend less time on motivating children and managing teamwork.

Additionally, in line with a wider trend in the field of CCl (e.g., McNally et al., 2017; Van Mechelen et al., 2018; 2019) it is worthwhile to investigate children's skill development throughout the CoDeT process. In the present case study, a positive evolution could be witnessed in children's interpersonal and small-group skills (e.g., turn taking, good questioning, arguing for a point of view), but additional research is required to more accurately evaluate these and other learning gains, such as children's design abilities and critical stance towards technology. Extending the objective from technology design to skill development in co-design activities with children can empower children beyond the design process, preparing them for the challenges of the $21^{\text {st }}$ century. CoDeT, developed for high child-to-adult ratios such as schools, maker spaces and museums, is well suited for this task.

\section{CONCLUSION}

This paper presented the CoDeT (Collaborative Design Thinking) approach, its theoretical framework, and its application in a case study with 49 children between 9 and 10 years old in two schools. CoDeT aims to scaffold children's collaboration and design thinking in co-design settings characterised by a high child-to-adult ratio (ca. 1 adult for 15 to 20 children) such as schools, museums and maker spaces. In these settings, challenges such as a lack of experience with teamwork and a limited understanding of the design process are amplified because children have to work relatively independently from adults who become guides on the side. To address these challenges, CoDeT relies on SIT (Johnson and Johnson, 2005), and the divergent-convergent DT model developed by Thoring and Müller (2011). According to SIT, which has been widely applied in Cooperative Learning approaches, five mediating principles are essential to set up a collaborative atmosphere and 
increase people's willingness to work together: positive interdependence, individual accountability, promotive interactions, adequate interpersonal and small-group skills, and group processing. SIT's principles are integrated in CoDeT to create optimal conditions for children to collaborate. The creative mechanisms of DT are used to enable children to explore and define the problem space, and to develop solutions by alternating between projective thinking to generate ideas (divergence) and reflective thinking on the impact of the projection (convergence).

The CoDeT approach is presented as a sequence of steps and although this linear structure may suggest little flexibility, the underlying theoretical framework (see Figure 3) allows design researchers to adapt the approach to the needs and specificities of different age cohorts and contexts.

\section{ACKNOWLEDGEMENTS}

Our gratitude goes to the 49 children who participated in the case study, and the school staff for their time and valuable feedback. The case study was part of the EMSOC project (grand number $\mathrm{nml} \mathrm{100027),} \mathrm{funded} \mathrm{by}$ IWT (Agency for Innovation by Science and Technology), and a PhD project funded by KU Leuven and Hasselt University (grand number 5/DWO/ 2007/11/B011).

\section{REFERENCES}

Ackerman, E., 2001. Piaget's Constructivism, Papert's Constructionism: What's the difference?

Alborzi, H., Druin, A., Montemayor, J., Platner, M., Porteous, J., Sherman, L., Boltman, A., Taxén, G., Best, J., Hammer, J., Kruskal, A., Lal, A., Schwenn, T.P., Sumida, L., Wagner, R., Hendler, J., 2000. Designing StoryRooms: Interactive Storytelling Spaces for Children, in: Proceedings of the 3rd Conference on Designing Interactive Systems: Processes, Practices, Methods, and Techniques, DIS '00. ACM, New York, NY, USA, pp. 95-104. https://doi.org/10.1145/347642.347673

Andersson, S., 1994. Social scaling and children's graphic strategies: A comparative study of children's drawings in three cultures. Linköping Studies in Arts and Science, Linköping.

Barendregt, W., Bekker, M.M., Börjesson, P., Eriksson, E., Torgersson, O., 2016. The Role Definition Matrix: Creating a Shared Understanding of Children's Participation in the Design Process, in: Proceedings of the 15th International Conference on Interaction Design and Children, IDC '16. ACM, New York, NY, USA, pp. 577-582. https://doi.org/10.1145/2930674.2935999

Barendregt, W., Börjesson, P., Eriksson, E., Torgersson, O., Bekker, T., Skovbjerg, H.M., 2018. Modelling the Roles of Designers and Teaching Staff when Doing Participatory Design with Children in Special Education, in: Proceedings of the 15th Participatory Design Conference: Full Papers - Volume 1, PDC '18. ACM, New York, NY, USA, pp. 9:1-9:11. https://doi.org/10.1145/3210586.3210589

Benton, L., Johnson, H., 2015. Widening participation in technology design: A review of the involvement of children with special educational needs and disabilities. Int. J. Child-Computer Interact. 3-4, 23-40. https://doi.org/10.1016/j.ijcci.2015.07.001

Brown, T., 2008. Design Thinking. Harvard Business Review. June 08, 84-92.

Dawes, A., 2000. Cultural diversity and childhood adversity: Implications for community level interventions with children in difficult circumstances. Presented at the Children in Adversity: An International Consultation on Ways to Reinforce the Coping Ability and Resilience of Children in Situations of Hardship, Refugee Studies Program, Oxford, UK.

Derboven, J., Van Mechelen, M., Slegers, K., 2015. Multimodal Analysis in Participatory Design with Children: A Primary School Case Study, in: Proceedings of the 33rd Annual ACM Conference on Human Factors in Computing Systems, CHI '15. ACM, New York, NY, USA, pp. 2825-2828. https://doi.org/10.1145/2702123.2702475

Deutsch, M., 1962. Cooperation and trust: Some theoretical notes. University of Nebraska Press, Lincoln.

Deutsch, M., 1949. A theory of cooperation and competition. Human Relations. 2, 129-152. 
Dillenbourg, P., 1999. What do you mean by collaborative learning?, in: Collaborative-Learning: Cognitive and Computational Approaches. Elsevier, Oxford, pp. 1-19.

Dodero, G., Gennari, R., Melonio, A., Torello, S., 2014. Towards Tangible Gamified Co-design at School: Two Studies in Primary Schools, in: Proceedings of the First ACM SIGCHI Annual Symposium on ComputerHuman Interaction in Play, CHI PLAY '14. ACM, New York, NY, USA, pp. 77-86. https://doi.org/10.1145/2658537.2658688

Donald, D., Wallis, J., Cockburn, A., 1997. An exploration of meanings: Tendencies towards developmental risk and resilience in a group of South African ex-street children. School Psychology International 18, 137154.

Druin, A., 2002. The role of children in the design of new technology. Behav. Inf. Technol. 21, 1-25.

Druin, A., 1999. Cooperative Inquiry: Developing New Technologies for Children with Children, in: Proceedings of the SIGCHI Conference on Human Factors in Computing Systems, CHI '99. ACM, New York, NY, USA, pp. 592-599. https://doi.org/10.1145/302979.303166

Druin, A., Weeks, A., Massey, S., Bederson, B.B., 2007. Children's Interests and Concerns when Using the International Children's Digital Library: A Four-country Case Study, in: Proceedings of the 7th ACM/IEEE-CS Joint Conference on Digital Libraries, JCDL '07. ACM, New York, NY, USA, pp. 167-176. https://doi.org/10.1145/1255175.1255207

Flick, U., 2009. An Introduction to Qualitative Research, Fourth Edition. ed. SAGE Publications Ltd, Los Angeles - London - New Delhi - Singapore - Washington DC.

Gibson, L., Sloan, D., Gregor, P., 2001. Using Children As Expert Web Evaluators, in: CHI '01 Extended Abstracts on Human Factors in Computing Systems, CHI EA '01. ACM, New York, NY, USA, pp. 147-148. https://doi.org/10.1145/634067.634157

Gielen, M.A., 2008. Exploring the child's mind - contextmapping research with children. Digital Creativity 19, 174-184. https://doi.org/10.1080/14626260802312640

Gielen, M.A., 2007. What's on a child's mind: Contextmapping research for designers' inspiration. Presented at the 1st International Symposium on Ludic Engagement Designs for All, Aalborg University, Esbjerg, pp. 26-29.

Golomb, C., 1992. The child's creation of the pictorial world. University of California Press, Los Angeles.

Guha, M., Druin, A., Fails, J., 2013. Cooperative Inquiry Revisited: Reflections of the Past and Guidelines for the Future of Intergenerational Co-design. Int. J. Child-Computer Interaction. Volume 1, 14- 23.

Guha, M.L., Druin, A., Chipman, G., Fails, J.A., Simms, S., Farber, A., 2004. Mixing Ideas: A New Technique for Working with Young Children As Design Partners, in: Proceedings of the 2004 Conference on Interaction Design and Children: Building a Community, IDC '04. ACM, New York, NY, USA, pp. 35-42. https://doi.org/10.1145/1017833.1017838

Horton, M., Read, J.C., Mazzone, E., Sim, G., Fitton, D., 2012. School Friendly Participatory Research Activities with Children, in: $\mathrm{CHI}$ '12 Extended Abstracts on Human Factors in Computing Systems, CHI EA '12. ACM, New York, NY, USA, pp. 2099-2104. https://doi.org/10.1145/2212776.2223759

Hourcade, J.P., 2008. Interaction Design and Children, in: Foundational Trends in Human-Computer Interaction, 1. NOW Publishers, Boston - Delft.

livari, N., Kinnula, M., Kuure, L., 2015. With best intentions: A Foucauldian examination on children's genuine participation in ICT design. Inf. Technol. People 28, 246-280. https://doi.org/10.1108/ITP-12-20130223

Iversen, O.S., Dindler, C., Hansen, E.I.K., 2013. Understanding teenagers' motivation in participatory design. Int. J. Child-Computer Interaction 1, 82-87. https://doi.org/10.1016/j.ijcci.2014.02.002

Iversen, O.S., Smith, R.C., Dindler, C., 2017. Child As Protagonist: Expanding the Role of Children in Participatory Design, in: Proceedings of the 2017 Conference on Interaction Design and Children, IDC '17. ACM, New York, NY, USA, pp. 27-37. https://doi.org/10.1145/3078072.3079725 
Johnson, D.W., Johnson, R.T., 2009. An Educational Psychology Success Story: Social Interdependence Theory and Cooperative Learning. Educ. Res. 38, 365-379. https://doi.org/10.3102/0013189X09339057

Johnson, D.W., Johnson, R.T., 2005. New Developments in Social Interdependence Theory. Genet. Soc. Gen. Psychol. Monogr. 131, 285-358.

Johnson, D.W., Johnson, R.T., 1999. Learning together and alone: Cooperative, competitive, and individualistic learning, 5th edition. ed. Allyn \& Bacon, Boston, MA.

Johnson, D.W., Johnson, R.T., 1994. Learning together and alone: Cooperative, competitive, and individualistic learning. Allyn \& Bacon, Boston, MA.

Johnson, D.W., Johnson, R.T., 1989. Cooperation and competition: Theory and research. Interaction Book Company, Edina, MN.

Kimbell, R., 2000. Critical concepts underpinning the Design \& Technology curriculum In England. Presented at the International Technology Education Conference, University of Brunswick, Brunswick.

Krol-Pot, K., 2005. Toward Interdependence: Implementation of Cooperative Learning in Primary Schools. Radboud Universiteit, Nijmegen.

Kryssanov, V.V., Tamaki, H., Kitamura, S., 2001. Understanding Design Fundamentals: How Synthesis and Analysis Drive Creativity, Resulting in Emergence. Al Eng. 15, 329-342.

Lewin, K., 1948. Resolving social conflicts. Harper, New York.

McNally, B., Mauriello, M.L., Guha, M.L., Druin, A., 2017. Gains from Participatory Design Team Membership As Perceived by Child Alumni and Their Parents, in: Proceedings of the $2017 \mathrm{CHI}$ Conference on Human Factors in Computing Systems, CHI '17. ACM, New York, NY, USA, pp. 5730-5741. https://doi.org/10.1145/3025453.3025622

Osborn, A.F., 1953. Applied imagination: Principles and procedures of creative problem-solving. Scribners, NY.

Papanek, V., 1985. Design for the Real World: Human Ecology and Social Change, 2 Revised edition. ed. Chicago Review Press, Chicago.

Plucker, J., Beghetto, R., Dow, G., 2004. Why isn't creativity more important to educational psychologists? Potentials, pitfalls, and future directions in creativity research. Educ. Psychol. 39, 83-96.

Read, J.C., 2008. Validating the Fun Toolkit: an instrument for measuring children's opinions of technology. Cogn. Technol. Work 10, 119-128. https://doi.org/10.1007/s10111-007-0069-9

Read, J.C., Fitton, D., Horton, M., 2014. Giving Ideas an Equal Chance: Inclusion and Representation in Participatory Design with Children, in: Proceedings of the 2014 Conference on Interaction Design and Children, IDC '14. ACM, New York, NY, USA, pp. 105-114. https://doi.org/10.1145/2593968.2593986

Read, J.C., Horton, M., Sim, G., Gregory, P., Fitton, D., Cassidy, B., 2013. CHECk: A Tool to Inform and Encourage Ethical Practice in Participatory Design with Children, in: $\mathrm{CHI}$ '13 Extended Abstracts on Human Factors in Computing Systems, CHI EA '13. ACM, New York, NY, USA, pp. 187-192. https://doi.org/10.1145/2468356.2468391

Read, J.C., Hourcade, J.P., Markopoulos, P., Druin, A., 2011. Child Computer Interaction Invited SIG: IDC Remixed, $\mathrm{CCl}$ Remapped, in: $\mathrm{CHI}$ '11 Extended Abstracts on Human Factors in Computing Systems, $\mathrm{CHI}$ EA '11. ACM, New York, NY, USA, pp. 689-691. https://doi.org/10.1145/1979742.1979540

Read, J.C., Markopoulos, P., 2013. Child-computer interaction. Int. J. Child-Computer Interaction 1, 2-6.

Resnick, L.B., 1991. Shared cognition: Thinking as a social practice, in: Perspectives on Socially Shared Cognition. American Psychological Association, Washington, DC, pp. 1-20.

Resnick, M., 2017. Lifelong Kindergarten: Cultivating Creativity through Projects, Passion, Peers, and Play. MIT Press, Cambridge, MA, USA.

Sanders, E.B.-N., Stappers, P.J., 2008. Co-creation and the new landscapes of design. CoDesign 4, 5-18. https://doi.org/10.1080/15710880701875068 
Sanders, E.B.-N., William, C.T., 2001. Harnessing People's Creativity: Ideation and Expression through Visual Communication, in: Focus Groups: Supporting Effective Product Development. Taylor \& Francis Group, Abingdon.

Sawyer, K., 2008. Group Genius: The Creative Power of Collaboration. Basic Books.

Scaife, M., Rogers, Y., 1999. Kids as informants: telling us what we didn't know or confirming what we knew already?, in: The Design of Children's Technology: How We Design, What We Design, and Why. Morgan Kaufman.

Scaife, M., Rogers, Y., Aldrich, F., Davies, M., 1997. Designing for or Designing with? Informant Design for Interactive Learning Environments, in: Proceedings of the ACM SIGCHI Conference on Human Factors in Computing Systems, CHI '97. ACM, New York, NY, USA, pp. 343-350. https://doi.org/10.1145/258549.258789

Schepers, S., Dreessen, K., Zaman, B., 2018. Rethinking children's roles in Participatory Design: The child as a process designer. Int. J. Child-Computer Interaction. https://doi.org/10.1016/j.ijcci.2017.12.001

Schuler, D., Namioka, A. (Eds.), 1993. Participatory Design: Principles and Practices. L. Erlbaum Associates Inc., Hillsdale, NY.

Shneiderman, B., 2000. Creating Creativity: User Interfaces for Supporting Innovation. ACM Trans ComputHum Interact 7, 114-138. https://doi.org/10.1145/344949.345077

Shuell, T.J., 1996. Teaching and learning in classroom context, in: Handbook of Educational Psychology. Macmillan, New York, pp. 726-764.

Sleeswijk Visser, F., Stappers, P.J., Van der Lugt, R., Sanders, E.B.-N., 2005. Contextmapping: experiences from practice. CoDesign 1 (2), 119-149. https://doi.org/10.1080/15710880500135987.

Spendlove, D., 2005. Creativity in Education: A Review. Des. Technol. Educ. Int. J. 10, 9-18.

Spinuzzi, C., 2005. The Methodology of Participatory Design. Tech. Commun. 52, 163-174.

Stokes, P.D., 1999. Novelty, in: Encyclopedia of Creativity. Academic Press, San Diego, CA, pp. 297-304.

Sutton, R.I., Hargadon, A., 1996. Brainstorming Groups in Context: Effectiveness in a Product Design Firm. Adm. Sci. Q. 41, 685-718.

Thoring, K., Müller, R.M., 2011. Understanding the Creative Mechanisms of Design Thinking: An Evolutionary Approach, in: Proceedings of the Second Conference on Creativity and Innovation in Design, DESIRE '11. ACM, New York, NY, USA, pp. 137-147. https://doi.org/10.1145/2079216.2079236

Van der Linden, J.L., Erkens, G., Renshaw, P., 1999. Collaborative Learning, in: New Learning. Kluwer Academic Publishers, Dordrecht, pp. 1-19.

Van Doorn, F., Stappers, P.J., Gielen, M., 2013. Design Research by Proxy: Using Children As Researchers to Gain Contextual Knowledge About User Experience., in: Proceedings of the SIGCHI Conference on Human Factors in Computing Systems, CHI '13. ACM, New York, NY, USA, pp. 2883-2892. https://doi.org/10.1145/2470654.2481399

Van Kesteren, I.E.H., Bekker, M.M., Vermeeren, A.P.O.S., Lloyd, P.A., 2003. Assessing Usability Evaluation Methods on Their Effectiveness to Elicit Verbal Comments from Children Subjects, in: Proceedings of the 2003 Conference on Interaction Design and Children, IDC '03. ACM, New York, NY, USA, pp. 4149. https://doi.org/10.1145/953536.953544

Van Mechelen, M., 2016. Designing technologies for and with children: Theoretical reflections and a practical inquiry towards a co-design toolkit. KU Leuven - UHasselt, Leuven.

Van Mechelen, M., Derboven, J., Laenen, A., Willems, B., Geerts, D., Vanden Abeele, V., 2017. The GLID method: Moving from design features to underlying values in co-design. Int. J. Hum.-Comput. Stud. 97, 116-128. https://doi.org/10.1016/j.ijhcs.2016.09.005

Van Mechelen, M., Derboven, J., Slegers, K., 2015a. Child-centered Design in Bullying Prevention: Play as Universal Antidote. Presented at CHI '15 workshop: Marshall, K., Wood, G., Read, J.C., Yarosh, S. L., Balaam, M. \& Lee, J.-J. (2015) Supporting Children to Engage in Play for Wellbeing. Seoul, South Korea. 
Van Mechelen, M., Gielen, M., Vanden Abeele, V., Laenen, A., Zaman, B., 2014a. Exploring Challenging Group Dynamics in Participatory Design with Children, in: Proceedings of the 2014 Conference on Interaction Design and Children, IDC '14. ACM, New York, NY, USA, pp. 269-272. https://doi.org/10.1145/2593968.2610469

Van Mechelen, M., Schut, A., Gielen, M., Södergren Clasina A., 2019. Children's Assessment of Co-design Skills: Creativity, Empathy and Collaboration, in: Proceedings of the 2019 Conference on Interaction Design and Children, IDC '19. ACM, New York, NY, USA.

Van Mechelen, M., Schut, A., Gielen, M., Klapwijk, R., 2018. Developing Children's Empathy in Co-design Activities: A Pilot Case Study, in: Proceedings of the 17th ACM Conference on Interaction Design and Children, IDC'18. ACM, New York, NY, USA, pp. 669-674. https://doi.org/10.1145/3202185.3210797

Van Mechelen, M., Sim, G., Zaman, B., Gregory, P., Slegers, K., Horton, M., 2014b. Applying the CHECk Tool to Participatory Design Sessions with Children, in: Proceedings of the 2014 Conference on Interaction Design and Children, IDC '14. ACM, New York, NY, USA, pp. 253-256. https://doi.org/10.1145/2593968.2610465

Van Mechelen, M., Zaman, B., Bleumers, L., Mariën, I., 2019. Designing the Internet of Toys for and witch Children: A Participatory Design Case Study, in: The Internet of Toys: Practices, Affordances and the Political Economy of Children's Play, Mascheroni G. \& Holloway, D. (eds.). Palgrave MacMillan.

Van Mechelen, M., Zaman, B., Laenen, A., Vanden Abeele, V., 2015b. Challenging Group Dynamics in Participatory Design with Children: Lessons from Social Interdependence Theory, in: Proceedings of the 14th International Conference on Interaction Design and Children, IDC '15. ACM, New York, NY, USA, pp. 219-228. https://doi.org/10.1145/2771839.2771862

Veale, A., 2005. Creative Methodologies in Participatory Research with Children, in: Researching Children's Experience. SAGE Publications Ltd, London - Thousand Oaks - New Delhi.

Walsh, G., Druin, A., Guha, M.L., Bonsignore, E., Foss, E., Yip, J.C., Golub, E., Clegg, T., Brown, Q., Brewer, R., Joshi, A., Brown, R., 2012. DisCo: A Co-design Online Tool for Asynchronous Distributed Child and Adult Design Partners, in: Proceedings of the 11th International Conference on Interaction Design and Children, IDC '12. ACM, New York, NY, USA, pp. 11-19. https://doi.org/10.1145/2307096.2307099

Walsh, G., Druin, A., Guha, M.L., Foss, E., Golub, E., Hatley, L., Bonsignore, E., Franckel, S., 2010. Layered Elaboration: A New Technique for Co-design with Children, in: Proceedings of the SIGCHI Conference on Human Factors in Computing Systems, CHI '10. ACM, New York, NY, USA, pp. 1237-1240. https://doi.org/10.1145/1753326.1753512

Walsh, G., Foss, E., Yip, J., Druin, A, 2013. FACIT PD: a framework for analysis and creation of intergenerational techniques for participatory design. Proceedings of the SIGCHI Conference on Human Factors in Computting Systems (CHI '13). New York, NY, USA. ACM, pp. 2893-2902. https://doi.org/10.1145/2470654.2481400.

Woodhead, M., 1999. Combating child labour: Listen to what the children say. Childhood: A Global Journal of Child Research 6, 27-49.

Yip, J.C., Sobel, K., Pitt, C., Lee, K.J., Chen, S., Nasu, K., Pina, L.R., 2017. Examining Adult-Child Interactions in Intergenerational Participatory Design, in: Proceedings of the $2017 \mathrm{CHI}$ Conference on Human Factors in Computing Systems, CHI '17. ACM, New York, NY, USA, pp. 5742-5754. https://doi.org/10.1145/3025453.3025787 


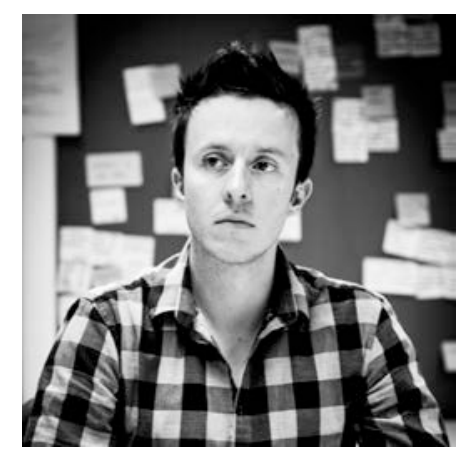

Maarten Van Mechelen is postdoctoral researcher at the Center for Computational Thinking and Design at Aarhus University, and affiliated researcher at the faculty of Industrial Design Engineering at TU Delft. He is specialized in the domain of Child-Computer Interaction; his current research focuses on critical digital design literacy and design-based learning. Before that, he worked on National and European research projects at the Meaningful Interactions Lab (KU Leuven - imec) where he worked on National and European research projects. Maarten obtained master degrees in Cultural Studies (VUB) and Graphic Design (PXL-MAD, UHasselt), and a doctoral degree in Design Research (KU Leuven - UHasselt). He is Associate Editor of the International Journal of Child-Computer Interaction and has been a committee member of the ACM Interaction Design \& Children Conference since 2018.

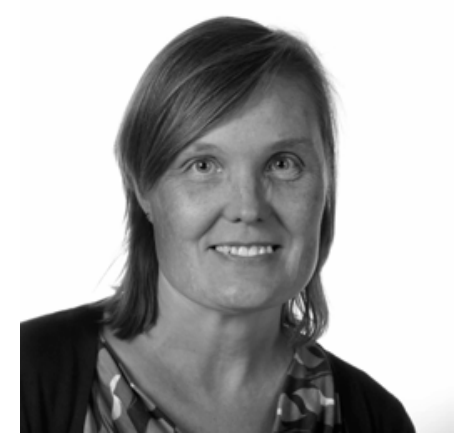

Ann Laenen studied Arts and Theatre Science and reached PhD level in 2007 on Arts Education. In 2009 she became the coordinator of the Communication Media Design - program at the Media \& Design Academy in Genk. October 2010 she became the Head of Department at that institution and two years later she was appointed Dean of the Faculty of the Arts (LUCA School of Arts / KU Leuven). Her research focus today is on arts/design education and interactive processes. At present she is teaching Active Design Processes at the Department of Digital Arts (University of Malta).

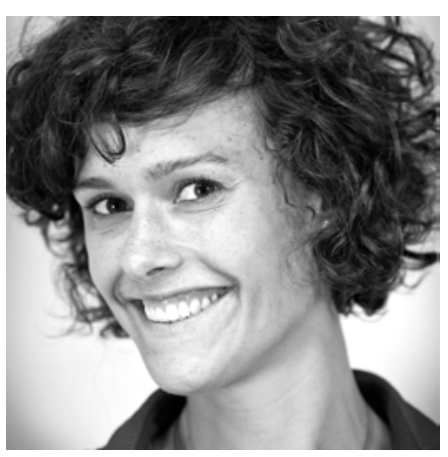

Bieke Zaman is assistant professor at Mintlab (KU Leuven - imec, Belgium). Her research focuses on digital media (incl. games), children and interaction design from the perspective of communication sciences and Human-Computer Interaction research. Bieke is member of several editorial boards (e.g., Associate Editor of the International Journal of Child-Computer Interaction, and Personal and Ubiquitous Computing), international conference committees (e.g., Vice-Chair of the ECREA TWG on Children, Youth and Media; 2017 Full Paper Chair, and 2013, 2015, 2016, 2018 Associate Chair of the Interaction Design and Children conference) and international networks (e.g., COST Action IS1410). 


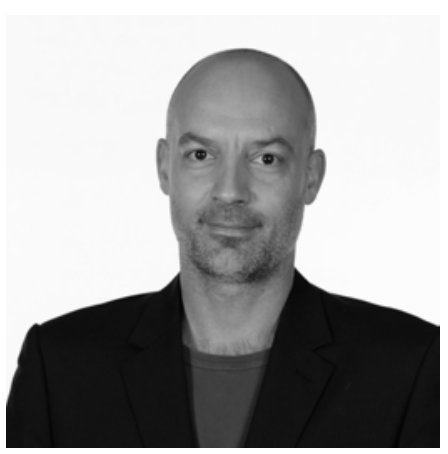

Bert Willems obtained his PhD in psychology and pedagogy at the University of Leuven. He is an associate professor at PXLMAD, Hasselt, and at Hasselt University (Faculty of Architecture \& Arts). Within the arts and design program of PXL-MAD and Hasselt University, he is responsible for research policy and the implementation of this policy. In his own research, he always starts from a cognitive view of the design process and the interesting interaction between culture and economy that many designers and artists like to use as a source for their creativity.

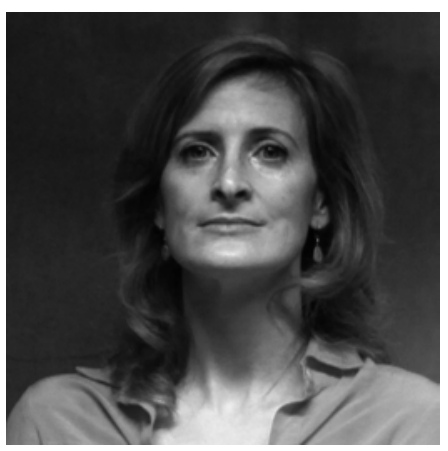

Vero Vanden Abeele is OP3 professor at the e-Media Lab of KU Leuven. She is active in the area of UX design, persuasive computing, motivational design, games for health, participatory design with young and old participants. Vero is member of several ACM SIGCHI program committees and steering committee member of the ACM CHI Play conference. She has been a co-applicant for several national and international research projects concerning serious games, health technology and children. 